\title{
EL PRINCIPIO DE COMPLEMENTARIEDAD EN EL ESTATUTO DE ROMA*
}

\section{Sergio GARCíA RAMÍREZ**}

RESUMEN: Una de las piezas fundamentales de la nueva jurisdicción penal internacional creada por el Estatuto de Roma es el denominado principio de complementariedad. Esto significa que la justicia internacional no desplaza a la justicia nacional, sino la complementa. Por ello, dicho principio puede considerarse como un espacio de convergencia y conciliación entre el concepto de soberanía, por una parte, y el concepto de operación y salvaguarda de un orden jurídico internacional, por la otra. En la operación de este principio es preciso tomar en cuenta el enlace que debe existir entre las atribuciones y posibilidades jurisdiccionales nacionales y las correspondientes al orden internacional. Tiene especial relevancia el problema que surge cuando el Estado nacional no lleva adelante el enjuiciamiento que, en principio, le corresponde con motivo de la comisión de delitos considerados en el Estatuto de Roma. En esta hipótesis aparecen los puntos de fricción más inquietantes entre ambos planos de la justicia penal.

ABSTRACT: One of the main aspects of the new international criminal jurisdiction created by the Rome Statute is the complementary principle, which entails that international justice does not displace the domestic justice, but rather complements it. Therefore, this principle shall be considered as a convergence and conciliation space between the concept of sovereignty on one hand, and the concept of operation and safeguard of an international legal order, on the other. When implementing this principle, the link that must exist between the domestic and the intemational jurisdictional attributions and possibilities ought to be taken into account. Particularly important becomes the problem that arises when a State commits one of the crimes considered in the Rome Statute and does not carry on the judgment that corresponds it since in the beginning. In this hypotheses take place the most disturbing friction points among both scenes of the criminal justice.

RÉSUMÉ: Une des piéces fondamentales de la nouvelle jurisdiction pénale internationale creé par le Statut de Rome est le principle de la complémentarieté, que signifie que la justice internationale ne déplace pas la justice nationale, mais la complète. Pour cet raison ce principle peut être consideré un espace de convergence et de conciliation entre le concept de souveraineté, d'un côté, et le concept d'operation et de sauvegarde d'un ordre juridique internacional, d'un autre côté. Dans l'instrumentation de ce principle c'est important s'apercevoir la liaison que doit avoir entre les attributions et les possibilités jurisdictionales nationales et les internationales. C'est particuliérement important le probléme que se deroule quand un État comit un crime compris dans le Statut de Rome et ne poursuit pas le mise en jugement que lui rendre. Dans cet hypothése arrivent les points de friction les plus inquiétantes entre les deux plans de la justice pénale.

* Este trabajo forma parte de un estudio sobre las relaciones entre la jurisdicción de la Corte Penal Internacional y las jurisdicciones nacionales, actualmente en preparación.

** Presidente de la Corte Interamericana de Derechos Humanos.

Anuario Mexicano de Derechr Intemacional, vol. IV, 2004 , pp. 149-188 
SUMARIO: I. Jurisdicción nacional e internacional. II. Complementariedad. Concepto y consecuencias. III. Ley nacional más benigna. IV. Ne bis in idem. V. Imprescriptibilidad. VI. Oportunidad conforme a la ley nacional. VII. Coincidencia o congruencia de normas. VIII. "Recuperación de la competencia".

\section{JURISDICCIÓN NACIONAL E INTERNACIONAL}

La creación de una zona de contacto entre las disposiciones del derecho internacional y las del derecho nacional renueva un tema difícil: la relación funcional y jerárquica entre aquél y éste. ${ }^{1}$ Sea cual fuere la solución de esta cuestión tan ardua, lo cierto es que la construcción de un derecho penal internacional ( $\mathrm{y}$ asimismo la de cualquier otro subsistema internacional que ponga frente a frente a los individuos y al Estado, ambos a título de partes en una controversia, como sucede en la tutela internacional de los derechos humanos) supone cierta deficiencia actual o potencial del orden nacional naturalmente competente; el internacional interviene entonces con aire de emergencia, y suele adoptar la regla de oro de la emergencia: poder inexorable.

Hay que resolver, por lo tanto, el orden de los personajes en la escena y las facultades de cada quien, así sea para decidir que uno tiene todas y el otro ninguna. A esto se refiere la complementariedad que el Estatuto de Roma - por el que se crea la Corte Penal Internacional- aborda con énfasis, tanto en sus razones como en sus disposiciones, ${ }^{2}$ aun cuando no define ni analiza —más allá del preámbulo y del artículo 10.- ese postulado, que sin embargo subyace en las normas sobre admisibilidad e impugnación de la competencia de la corte. ${ }^{3} \mathrm{La}$ indmisibilidad se resuelve, precisamente, al amparo del décimo párrafo del preámbulo y del artículo

1 Es abundante la literatura sobre este asunto. Entre los títulos de aparición más reciente figura la obra de carácter panorámico: Ayala Corao, Carlos M., La jerarquía constitucional de los tratados relativos a derechos humanos y sus consecuencias, Querétaro, México, Colección Fundap, Derecho, administración y politica, 2003.

2 En el preámbulo, los Estados destacan "que la Corte Penal Internacional establecida en virtud del presente estatuto será complementaria de las jurisdicciones penales nacionales", y en esto abunda, como antes vimos, el artículo lo.: la CPI "tendrá carácter complementario de las jurisdicciones penales nacionales".

3 Cfr. Quezada, Alejandra, "El mecanismo de activación de competencia de la Corte Penal Internacional”, Diplomacia, Chile, núm. 3, diciembre de 2002, pp. 104-106. 
1o. del estatuto (artículo 17.1). En fin, la complementariedad es "un límite al ejercicio de la jurisdicción de la CPI y una salvaguarda de la soberanía de los Estados". ${ }^{4}$

Esta es una cuestión de superlativa importancia que se zanja en el derecho constitucional, ${ }^{5}$ cuando éste regula el papel de los tratados $-\mathrm{y}$, en general, de las normas internacionales-con respecto al ordenamiento interno, ${ }^{6}$ y sobre todo en el derecho de gentes mismo, que fija sus reglas y dispone sus fronteras, con sustento - en principio y por lo pronto- en el ejercicio soberano de los Estados. La renuncia primigenia bajo el roble legendario, que hizo posible el "contrato original", se reproduce en el pacto internacional y también en el acuerdo de todos los días: la costumbre que puede engendrar un jus cogens, nada menos. A partir de aquí se pone en pie una nueva arquitectura jurídica, particularmente densa e intensa en tiempos de mundialización, como los nuestros.

El crimen, que fue un hecho doméstico, ha desbordado sus linderos tradicionales. No haré una reseña de este proceso, perfectamente sabido. ${ }^{7}$ De ese desbordamiento - entre otras causas - deriva el aparato persecutorio moderno, que sirve a una divisa beccariana: que no haya un lugar en el mundo - -se dijo en De los delitos y las penas, hace más de dos siglos- en que halle refugio el criminal. ${ }^{8}$

4 "No cabe duda que la jurisdicción de la CPI es atribuida y, por tanto, esencialmente limitada. Los Estados transfieren a la corte una competencia (soberana) que les es propia (y muy sensible): el ejercicio (subsidiario) de la jurisdicción penal, que en ningún caso es un asunto esencialmente de la jurisdicción interna de los Estados por la gravedad de los crímenes de que se trata y su trascendencia para la comunidad internacional". Alcaide Fernández, Joaquín, "La complementariedad de la Corte Penal Internacional y de los tribunales nacionales: ¿ticmpos de “ingeniería jurisdiccional'?", en Carritlo Salcedo (coord.), La criminalización de la barbarie..., cit. En el mismo sentido, Armenta Deu. "La comunicación entre la Corte Penal Internacional y los Estados", en Ibarra Romo, I. (comp.), La soberania de los Estados y la Corte Penal Internacional. Memoria del Foro Internacional, México, LIV Legislatura del Estado de México-Comisión de Derechos Humanos del Estado de México-Comisión Nacional de los Derechos Humanos, 2002, p. 220.

5 "El cumplimiento de las disposiciones del Estatuto de la CPI depende en gran medida de las normas que a nivel interno existan en cada país relativas a la aprobación, cumplimiento y jerarquía de los tratados". Comisión Andina de Juristas, La Corte Penal Internacional y los países.... cit.. p. 29.

6 Cfr. García Ramírez, Sergio, Iss derechos Intmanos y la jurisdicción interamericana, México, UNAM, Instituto de Investigaciones Jurídicas, 2002, pp. 46 y 47.

7 Cfr. García Ramírez. Sergio. Iss derechos humanos y el derecho penal, 2a. ed., México, Miguel Ángel Porrúa, 1988, pp. 191 y ss.

8 "Dentro de los confines de un país jescribió César Beccaria, que en este punto se refería al antiguo sistema del asilol no debería haber ałgún lugar independiente de las leyes. Su poder debería seguir a todo ciudadano como la sombra al cuerpo... la persuasión de no encontrar un palmo de tierra que perdonase a los verdaderos delitos sería un medio eficacísimo de evitarlos". Beccaria. César. De los delitos y de las penas, trad. de Juan Antonio de las Casas, ed. facsimilar con est. introd. de Sergio García Ramírez, México, Fondo de Cultura Económica, 2000, pp. 303 y 304. 
La persecución se atiene, tradicionalmente, a determinadas reglas: territorialidad - forum delicti-, nacionalidad del sujeto activo, nacionalidad del sujeto pasivo y protección. Cada una significa un paso adelante en los poderes del Estado nacional, que invoca una jurisdicción territorial, una jurisdicción personal -más allá del territorio: dondequiera que vayan los nacionales - y una jurisdicción material - hasta donde lleguen los intereses del Estado-.

Estas reservas competenciales se hallan firmemente enlazadas con la facultad soberana del Estado. "Si en algún lugar se han atrincherado tradicionalmente las prerrogativas de la soberanía del Estado - se ha escrito- ese lugar ha sido justamente el derecho penal".?

Sin embargo, esas reglas no bastan para esta era. El derecho penal nacional, tutelar de bienes jurídicos, tiene una cantera cierta: la Constitución democrática. ${ }^{10}$

El derecho penal internacional posee la suya propia: el jus cogens, recogido por las normas convencionales ${ }^{11} \mathrm{y}$ analizado por la jurisprudencia y la doctrina, ${ }^{12}$ y los instrumentos fundamentales del orden jurídico de

9 Lamarca Pércz, Carmen, "El principio de justicia universal y la competencia de la jurisdicción española en los casos de Argentina y Chile”, en varios, Homenaje al Dr. Marino Barbero Santos. In memoriam, dirigido por Luis Arтoyo Zapatero e Ignacio Berdugo Gómez de la Torre, Ed. de la Universidad de Castilla, La Mancha-Ed. Universidad Salamanca, Cuenca, 2001, vol. I, p. 1100.

10 Claus Roxin señala, al ocuparse en el tema del bien jurídico: "El punto de partida correcto consiste en reconocer que la única restricción previamente dada para el legislador se encuentra en los principios de la Constitución. Por tanto, un concepto de bien jurídico vinculante político criminalmente sólo se puede derivar de los cometidos, piasmados en la Ley Fundamental, de nuestro Estado de derecho basado en la libertad del individuo, a través de los cuales se le marcan sus límites a la potestad punitiva del Estado". Roxin, Claus, Derecho penal. Parte general, trad. de Diego-Manuel Luzón Peña, Miguel Diaz y García Conlledo y Javier de Vicente Remesal, Madrid, Ed. Civitas, 1997, t. I, pp. 55 y 56. Las Constituciones de la segunda postguerra han elaborado un código de valores que figuran como límites al jus puniendi. "Si el sistema penal está vinculado a la protección de intereses relevantes por exigencia constitucional, dichos intereses han de tener necesariamente un reconocimiento - más o menos explícito- en la propia Constitución". García Rivas, Nicolás, El poder punitivo en el Estado democrático, Cuenca, Ed. de la Universidad de Castilla-La Mancha, 1996, pp. 43 y ss. Cfr. la discusión del tema en González-Salas Campos, Raúl, La teoria del bien jurídico en el derecho penal, México, Pereznieto Ed., 1995, pp. 41 y ss.

11 El articulo 53 de la Convención de Viena sobre el Derecho de los Tratados caracteriza la norma imperativa de derecho intemacional general (jus cogens) como "una norma aceptada y reconocida por la comunidad internacional de Estados en su conjunto como norma que no admite acuerdo en contrario y que sólo puede ser modificada por una norma ulterior de derecho internacional general que tenga el mismo carácter".

12 Se ha destacado el carácter jus cogenti de dos conjuntos normativos: "el primero, los artículos más significativos de la Carta de las Naciones Unidas, entre ellos, con mayor insistencia, los artículos $20 ., 33$ y 51 , es decir, la proscripción deł uso de la fuerza, la solución pacífica de los conflictos y la legítima defensa. Fl segundo, la protección de los derechos humanos fundamentales, aduciéndose al efecto, cono normas imperativas, la prohibición de la esclavitud, del genocidio, de la discrimina- 
gentes, construido para proteger los derechos de las personas, pero también las atribuciones de los Estados.

Al señalar esto último, pienso en el tema de la agresión, una asignatura pendiente, explícitamente, en el Estatuto de Roma. De este modo se nutre la formulación de los tipos penales internacionales, desde la agresión y los crímenes de guerra hasta el genocidio y los delitos de lesa humanidad. La preocupación por amparar esos bienes con el escudo que provee - muy limitado, es cierto- la conminación penal, se ha depositado en varios círculos concéntricos del orden jurídico: la ley interna, los convenios sobre crímenes o delitos específicos y el Estatuto de Roma.

Las ideas de que hay bienes comunes a la humanidad en su conjunto, ya no sólo reservados a una persona, un grupo o una nación, y de que eso trae consigo una represión verdaderamente mundial $-\mathrm{y}$ por ello realmente eficaz - de los crímenes que lesionan los bienes comunes, puso en movimiento -y ahora en boga- la pretensión y el principio de persecución universal, en sus dos dimensiones prevalecientes: persecución por cualquier Estado más allá de sus fronteras formales, ${ }^{13}$ y persecución por los Estados en conjunto, sea porque éstos resuelvan hacer, asociados, lo que podría cada quien por su parte, como se dijo en Nüremberg, sea porque la comunidad de bienes y la unión de fuerzas supongan una nueva potestad. Entre esas dos pretensiones, que entran en colisión en el punto donde termina el poder (jurídico, quiero decir) nacional y comienza el internacio-

ción racial, y luego, los principios cardinales en la conducta de las hostilidades y el derecho humanitario". Gómez Robledo, Antonio, El jus cogens internacional (Estudio histórico-crítico), México, UNAM, Instituto de Investigaciones Juridicas, 1982, p. 185. Este autor coincide con dos definiciones de jus cogens: la del español Antonio de Luna: "El mínimo esquema jurídico que la comunidad internacional considera indispensable para su existencia en un momento determinado", y la del mexicano Eduardo Suárez: "aquellos principios que la conciencia jurídica de la humanidad, revelada por sus manifestaciones objetivas, considera como absolutamente indispensables para la coexistencia y la solidaridad de la comunidad internacional en un momento determinado de su desarrollo orgánico". Gómez Robledo, Antonio, op. cit., en esta misma nota, p. 227. Alfred Verdross menciona, entre las normas de jus cogens, los principios constitucionales fundamentales acerca de la subjetividad jurídica internacional y las fuentes del derecho internacional, el principio del respeto mutuo entre los Estados, el principio de buena fe que informa todo el tráfico jurídico internacional, el principio de que no tienen fuerza obligatoria los tratados inmorales y los que violan los principios de humanidad. Cfr. Verdross, Alfred, Derecho internacional público, trad. de Antonio Truyol y Serra, Madrid, Aguilar, 1957, p. 81.

13 Cfr. Lamarca Pérez, Carmen, op. cit., nota 9, p. 1102, y Guevara B., José A., "México frente a la jurisdicción universal: la extradición de Ricardo Miguel Cavallo", Revista Mexicana de Derecho Público, núm. 3, abril de 2002, pp. 73 y ss. 
nal, existe cierta tensión pendiente de buen arreglo. Podría traerlo, como adelante diré, el sistema creado por el Estatuto de Roma.

La jurisdicción universal ejercida por los Estados —expresión de una vigorosa corriente contra la impunidad, ${ }^{14}$ animada sobre todo en los últimos lustros, ${ }^{15}$ y cuyo sustrato es la existencia de delitos contra la humanidad (delicti jus gentium) que afectan los intereses de todos los Estados- ${ }^{16}$ resulta ser un sistema a media vía entre el sistema de persecución por factores estrictamente nacionales (lo son el territorio, la nacionalidad de los protagonistas y el interés del Estado) y la persecución en manos de una instancia verdaderamente internacional, que actúa en función de bienes y disposiciones del mismo carácter. Esta última funciona - como se hizo ver en Roma- para ejercer institucionalmente una competencia que ya poseen, individualmente, algunos Estados conforme a sus normas nacionales. ${ }^{17}$

Nótese que este criterio parece naturalmente aplicable cuando hay interés mundial en la represión de ciertos delitos, pero se carece de un órgano "no nacional" - -auténticamente representativo de ese interés general- que lo haga. Si surge aquel órgano, que no se halle acotado por motivos de persona, espacio o tiempo —como lo han estado y lo están los tribunales circunstanciales o ad-hoc- cesa la razón de ser de la jurisdicción universal en manos de los Estados. Conviene analizar y resolver la coexistencia de la potestad persecutoria en los Estados y en la nueva jurisdicción internacional, indistintamente, o el desplazamiento de aquélla por ésta. Se ha dicho, no sin razón, que "el carácter complementario de la

14 Cfr. Díaz Müller, Luis T., "Globalización y jurisdicción universal: un estudio de caso", Boletin Mexicano de Derecho Comparado, nueva serie, año XXXV, núm. 105, septiembre-diciembre de 2002 , pp. 860 y ss.

15 Alemania, Austria, Dinamarca y los Países Bajos desplegaron su jurisdicción sobre delitos cometidos con motivo del conflicto en la antigua Yugoslavia; Bélgica, Francia y Suiza lo hicieron en relación con crímenes perpetrados en Ruanda; Italia y Suiza investigaron delitos cometidos durante los años de la dictadura militar argentina (1976-1983), y España, Bélgica, Francia y Suiza actuaron con respecto a hechos durante el gobierno de Pinochet en Chile. En los años siguientes a la Segunda Guerra, muy pocos Estados mantuvieron en su derecho interno la jurisdicción universal sobre delitos de lesa humanidad y crímenes de guerra: Australia, Canadá, Israel, Reino Unido. Cfr. Amnistía Internacional, "La jurisdicción universal: catorce principios fundamentales sobre el ejercicio eficaz de la jurisdicción universal", en http://iccnow.org/html/ail99904.spanish.htm/.

16 Cfr. Gómez-Robledo Verduzco, Alonso, "El alegato de 'genocidio' y de 'jurisdicción universal' en casos de extradición internacional", Jurídica, México, núm. 30, 2000, p. 78.

17 Cfr. Schabas, William A., An introduction to the International Criminal Court, Cambridge, Cambridge University Press, 2001, p. 61. 


\section{CPI, junto a las pretensiones exorbitantes de las jurisdicciones nacionales} para conocer de crímenes internacionales pueden hacer ilusorias las competencias de la corte". 18

Cuando no había tribunales penales internacionales y se requería ampliar el espacio de la persecución, pareció natural el ejercicio del principio universal en manos de los Estados. Algunos -ciertamente no todos- lo asumieron y lo ejercieron, hasta vistosamente. Se hizo o se hace por diversas vías, a las que no fueron ajenas ni la extradicción ni el secuestro, ${ }^{19}$ "regularizados" bajo el concepto male captus bene detentum, ${ }^{20}$ que han provocado decisiones desconcertantes y controvertidas. ${ }^{21}$ Sea lo que fuere, estas incursiones de varios Estados en el procesamiento de delitos de lesa humanidad ha atraído el interés general hacia la causa de la justicia. ${ }^{22}$ Ahora bien, instituida una jurisdicción universal, que

18 Rodríguez Carrión, Alejandro J., "Una evaluación no necesariamente crítica del Estatuto de la Corte Penal Internacional", en Carrillo Salcedo (coord.), op. cit., nota 4, p. 495.

19 Cfr. un panorama de esta materia en González Oropeza, Manuel, Secuestrar para juzgar. Pasado y presente de la justicia extraterritorial, México, UNAM, Instituto de Investigaciones Jurídicas, 1998; Gómez-Robledo Verduzco, Alonso, Extradición en derecho internacional. Aspectos y ten. dencias relevantes, México, UNAM, Instituto de Investigaciones Jurídicas, 2000.

20 La máxima fue aceptada por la Suprema Corte de Justicia, por unanimidad de sus magistrados, en el caso Frisbie v. Collins, de 1952. Cardozo, Michacl H., "When extradition fails, is abduction the solution?", en Muller, G., y Wise, E., Intemational Criminal Law, Nueva York, Fred B. Rothman \& Co-Sweet \& Maxwell Limited, 1965, p. 471. A partir de un caso en la jurisprudencia estadounidense. correspondiente al prófugo Andrija Artukovic, cuya extradición fue insistentemente solicitada por Yugoslavia a los Estados Unidos de América, sin éxito, por crímenes cometidos durante la Segunda Guerra, el autor se plantea la legitimidad del secuestro como alternativa para que el Estado requirente pueda hacer justicia.

21 Es bien conocida y ha sido muy cuestionada la sentencia de la Suprema Corte de Justicia de los Estados Unidos de América, det 16 de junio de 1992, en el caso United States vs. Humberto Álvarez Machain (en recurso de certiorari de la Corte de Apelaciones de los Estados Unidos de América para el Noveno Circuito), proyectada por el juez Rehnquist y apoyada por los jueces White, Scalia, Kennedy, Scouter y Thomas. Disintieron los jueces Stevens, Blackmun y O'Connor. Un importante precedente no adoptado en la sentencia Álvarez Machain, se produjo en el caso United States vs. Verdugo Urquidez, Corte de Apelaciones para el Noveno Circuito, 22 de julio de 1991. Cfr. Secretaría de Relaciones Exteriores, Limites de la jurisdicciôn nacional. Documentos y resoluciones judiciales del caso Alvarez Machain, México, 1992, vol. I, y 1993, vol. II. Sobre este asunto, véase, asimismo, la argumentación de Hugo B. Margáin, en el prólogo a Smith. Peter H. (comp.), El combate a las drogas en América, México, Fondo de Cultura Económica, 1993, pp. 11 y ss.; y Gómez-Robledo Verduzco. Alonso, Extradición..., cit., nota 19, pp. 31 y ss. Hoy existe un tratado entre el gobierno de los Estados Unidos Mexicanos y el gobierno de los Estados Unidos de América, de 23 de noviembre de 1994 , que prohibe los secuestros transfronterizos.

22 El caso del ex-dictador chileno Augusto Pinochet es el de mayor relevancia en los últimos años. Cfr. Gómez-Robledo Verduzco. Alonso, "El ałegato...", cit., nota 16, pp. 59 y ss. En este caso también era aplicable el principio de protección, tomando en cuenta que entre tas víctimas de la represión en Chile había más de cineuenta argentinos: pero no existía, en rigor, genocidio (por falta del dato subjetivo en relación con la nacionalidad de los españoles) - señala Gabriela Rodríguez - ni 
encarna en la Corte Penal Internacional, pudiera haber llegado el momento de revisar estas persecuciones, para "poner orden en el orden penal" -valga el énfasis-, pero también para evitar lo que se ha denominado forum shopping, ${ }^{23}$ que es una puerta de acceso a la benevolencia punitiva o de plano a la impunidad. ${ }^{24}$

Si la jurisdicción universal en manos de los Estados es un sistema de media vía para asegurar la sanción y evitar la impunidad cuando no existan otros medios plausibles, ${ }^{25}$ su razón de ser declina cuando aparece un órgano permanente de justicia internacional idóneo para concentrar las atribuciones persecutorias que se dispersaron en poder de los Estados. Si esto sucede, sería razonable entender que sólo debiera subsistir aquélla persecución estatal en cuatro hipótesis: a) En relación con delitos cometidos fuera del ámbito de vigencia temporal del estatuto (anteriores al momento en que éste entró en vigor en forma general o para determinados Estados en particular); ${ }^{26}$ b) Cuando el Estado que persigue no es parte en el Estatuto de Roma; c) Sobre delitos no incluidos en éste —el estatuto no agota el catálogo del derecho penal internacional-, y $d$ ) En el supues-

eran competentes los tribunales españoles al amparo del artículo VI de la Convención sobre genocidio. Cfr. Rodríguez, Gabriela, "Algunas consideraciones en torno a la jurisdicción universal", Revista Mexicana de Derecho Público, núm. 1, febrero de 2002, p. 204. Acerca de este asunto, es particularmente rejevante la tesis sustentada por la mayoría de los lores que integraron el Comité de Apelación de la Cámara de los Lores en el conocimiento de este caso en el Reino Unido, analizando la cuestión de la inmunidad con respecto a actos de un jefe de Estado y negando que las conductas criminales atribuidas a Pinochet pudiesen ser consideradas como "actos oficiales de un jefe de Estado" y quedar, en consecuencia, amparadas por el principio de inmunidad. Este fue el parecer de los jueces lord Steyn, lord Nicholls y lord Hoffman. La notable sentencia se dictó el 25 de noviembre de 1998. Cfr. Lagos Erazo, Jaime, El "caso Pinochet" ante las cortes británicas, Santiago de Chile, Ed. Jurídica de Chile, 1999 , pp. 35 y ss., y 169 y ss. También relevante $-\mathrm{y}$ desde luego conocido en México- ha sido el procedimiento de extradición del argentino Ricardo Miguel Cavallo. Cfr. Guevara B., op. cit., nota 13, pp. 69 y ss. Finalmente, en sentencia del 10 de junio del 2003, la Suprema Corte de Justicia de México reconoció la pertinencia de la extradición de Cavallo a España, para atender el pedimento formulado por este país en virtud del principio de jurisdicción universal.

23 Se trata de la búsqueda y elección del ámbito jurisdiccional más favorable para el inculpado, tomando en cuenta las circunstancias del caso. Cfr. la opinión de A. J. Rodriguez Carrión, a este respecto, citado por Alcaide Fernández, Joaquín, op. cit., nota 4, pp. 421 y ss.

24 Desde luego, hay importantes opiniones en sentido diferente; así, Amnistia Internacional sostiene que "los Estados deben garantizar que sus tribunales ejerzan en nombre de la comunidad internacional la jurisdicción internacional sobre los delitos graves comprendidos en el derecho internacional". Cfr. "La jurisdicción universal...", en http://iccnow.org/html/ail99904.spanish.htm/.

25 "El principio de justicia universal debe operar pues con carácter supletorio para aquellos casos graves donde existe un peligro cierto de que los crimenes queden en la más absoluta impunidad". Lamarca Pérez, Carmen, op. cit., nota 9, p. 1102.

26 Cfr. Schabas, William A., op. cit., nota 17, p. 57 
to de que la corte hubiese declinado el conocimiento, por tratarse de hechos de escasa gravedad o que no interesen a la justicia. ${ }^{27}$ Considero que esta regla debiera prevalecer incluso frente a la alternativa jurisdiccional abierta por el artículo VI de la Convención sobre el castigo del genocidio. ${ }^{28}$ Sin embargo, no parece haber una tendencia en el sentido de suspender o desechar la jurisdicción universal ejercida por los Estados. ${ }^{29}$

La misma o semejante consideración se puede aplicar a otros tribunales del orden penal internacional. No parece conveniente ni pertinente multiplicar estas jurisdicciones mediante nuevas cortes ad-hoc. En lo que pudiéramos llamar la "historia natural de la jurisdicción penal internacional", aquéllas corresponden a una etapa anterior a la que hoy pretendemos realizar. En el iter de la justicia internacional, aparecieron y actuaron cuando la jurisdicción universal de los Estados no podía operar con eficacia o no se interesaba en hacerlo, y todavía no se contaba con una corte permanente nativa del consenso de la comunidad internacional, o al menos de una parte significativa de ésta, lo que significa, por otra parte, que la CPI ha sido establecida con el "consentimiento de quienes pudieran quedar sujetos a su jurisdicción" ${ }^{30}$ Habría que meditar sobre esta cuestión no sólo por lo que toca a futuros tribunales ad-hoc como los de la ex-Yugoslavia y Ruanda, sino también por lo que se refiere a otras juris-

27 Por supuesto, hay diversas opiniones sobre este punto. Se ha dicho que la jurisdicción universal de los Estados no entra en conflicto con la competencia de la corte; se trata de mecanismos complementarios. E1 funcionamiento de la corte no excluirá la jurisdicción universal estatal "concretamente frente a delitos internacionales cometidos antes de la vigencia del estatuto, asi como en aquellos casos donde algún Estado haga valer el principio de competencia preferente frente a la corte en virtud de la naturaleza complementaria de este mecanismo". Defensoria del Pueblo, La Corte Penal Internacional. Estatuto de Roma, Lima, Perú, 2000, p. 14.

28 La opción de que el juez nacional conozca de casos de genocidio cometido fuera de su ámbito de competencia territorial, aplicando la regla de jurisdicción universal no es pacíficamente aceptada. Cfr. Gutiérrez Baylón, Juan đe Dios, "La doctrina de la jurisdicción o competencia universal y el principio del unilateralismo en materia de derecho humanitario internacional", Lex, México, 3a. época, año VII, núm. 91 , enero de 2003 , pp. 18 y ss.

29 Entre los problemas cuya solución se halla pendiente, a propósito de la coexistencia -en su caso- de la jurisdicción internacional ejercida por la CPI y la pretensión de jurisdicción universal de un Estado, Carolina Susana Anello menciona uno: "determinar si la corte (PI) cederá su competencia conforme al principio de complementariedad incluso en el caso en que el Estado que se arrogue la competencia del enjuiciamiento lo haga sobre la base del principio de justicia universal, o si sólo tendrá efectos el principio de complementariedad en el caso en que el Estado tenga alguna relación con el crimen en cuestión". Anello, Carolina Susana, Corte Penal Internacional creada por el Estatuto de Roma (17/7/98), Buenos Aires, Ed. Universidad, 2003, p. 44. La misma autora examina algunos problemas que se manifiestan en la posible concurrencia de competencias entre la CPI y un Estado que ejerce su jurisdicción universal. Anello, Carolina Susana, op. cit., en esta misma nota, pp. 98 y ss.

30 Schabas, op. cit., nota 17, p. 54. 
dicciones establecidas a través de acuerdos entre Naciones Unidas y determinados gobiernos; así, la de Sierra Leona, que tiene características singulares. ${ }^{31}$

\section{COMPLEMENTARIEDAD. CONCEPTO Y CONSECUENCIAS}

El encuentro entre el poder nacional y el poder internacional se resolvió en Nüremberg y Tokio de una manera bien conocida: el vencedor dictó sus leyes, erigió sus tribunales, realizó sus juicios y ejecutó sus sentencias. Lo digo sin calificación. Eso sucedió. Algunos juristas demócratas, como Jiménez de Asúa, que denuncia "el sentido reaccionario de lo que les parecía a las gentes la máxima acción revolucionaria", hubieran preferido que la justicia se administrara de otra manera: en forma sumaria, expeditiva, como acto de revolución. ${ }^{32}$ En la ex-Yugoslavia y Ruanda, la jurisdicción se instaló desde arriba, no por los vencedores, sino por el organismo internacional que interpretaba sus atribuciones y las extendía -0 identificaba, si se prefiere- en forma conveniente: el Consejo de Seguridad de las Naciones Unidas ${ }^{33}$ erigió unos tribunales que desplazaron a la

31 Tras un prolongado trabajo en la negociación de un acuerdo de Naciones Unidas con Sierra Leona, conforme a la resolución 1315/2000 del Consejo de Seguridad (14 de agosto de 2000), el 16 de enero de 2002 se suscribió el Acuerdo entre las Naciones Unidas y el Gobierno de Sierra Leona acerca del establecimiento de un Tribunal Especial para Sierra Leona. Este órgano pactado tiene competencia para "procesar a las personas a quienes quepa la mayor responsabilidad por las infracciones graves del derecho internacional humanitario y el derecho de Sierra Leona cometidas en el territorio de ese país a partir del 30 de noviembre de 1996" (énfasis agregado) (artículo 1.1); se integra con salas de primera instancia y sala de apelaciones; en cada una de aquéllas figuran un magistrado designado por el gobiemo de Sierra Leona y dos por el secretario general de Naciones Unidas, y en la de apelaciones participan dos magistrados nombrados por dicho gobierno y tres por el secretario general (artículo 2.2). Sobre este "tribunal sui generis", cfr. Anello, Carolina Susana, op. cit., nota 29 , pp. 25 y ss.

32 Sigue diciendo ese autor: "el enjuiciamiento de los criminales de guerra no era otra cosa... que el recurso conservador de los anglosajones contra la necesaria justicia expeditiva". Jiménez de Asúa, "El juicio de Nüremberg", Criminalia, México, año XXIV, núm. 6, junio de 1948, p. 251. "Cuando un problema inmenso ha surgido en un pueblo o en el globo, no es posible acudir al Código Penal..., que está hecho para el ladrón y el homicida comunes; es preciso algo mucho más grande, más intenso y profundo". Jiménez de Asúa, op. cit., en esta misma nota, pp. 254 y 255 . Sobre el carácter "revolucionario" - -en otro sentido- que pudo revestir el Tribunal Militar Internacional de Nüremberg, cfr. Jescheck, Hans Heinrich, Tratado de derecho penal. Parte general, trad. de S. Mir Puig y F. Muñoz Conde, Barcelona, Bosch, 1981, vol. I, p. 162.

33 Se ha criticado severamente a los tribunales ad-hoc: en la creación de éstos "ha primado el interés político sobre las exigencias de la justicia... Es evidente que se ha scguido un criterio selectivo al efecto, ya que si no habría que plantearse el por qué de la orfandad juridico internacional de otros conflictos recientes, o aún en curso, como los de Angola, Sudán, Burindi o Chechenia, entre otros". Peláez Marón, José Manuel, "El desarrollo del derecho internacional penal en el siglo XX", en Carri- 
justicia nacional, absolutamente impotente, por lo demás, para hacer su cometido; excluida o reducida ésta, aquélla prevalece..$^{34}$

La solución de Roma - como las que se crearon previamente a propósito de los litigios sobre derechos humanos- ${ }^{35}$ marchó en otra dirección: reconoció que el compromiso, el derecho y la jurisdicción corresponden, en primer lugar -o en primera línea, acaso mejor--, al Estado particular, y sólo después, en defecto de éste, a la comunidad internacional. Empero, esto significa que exista, pura y llanamente, una primacía de la jurisdicción nacional sobre la internacional. ${ }^{36}$ Aquí hay un reconocimiento de doble espectro: jurídico, que no cancela, sino alienta y observa el derecho originalmente aplicable; y político, que admite la función protagónica de los Estados en el orden internacional, y sabe que sin éstos o contra ellos difícilmente habría justicia sistemática y suficiente. En este último sentido, pues, complementariedad significa también excepcionalidad; de no ser así, sobrevendría el colapso de la justicia internacional, como ocurriría con la nacional si no existiesen vías alternas para la satisfacción de las pretensiones y la solución de los litigios.

El Convenio, también de Roma, de 1950, y la Convención Americana sobre Derechos Humanos, de 1969, han establecido una jurisdicción internacional complementaria de la nacional, pero no arrasadora de ésta. De ahí la regla de agotamiento previo de los procedimientos internos, ${ }^{37}$ un

Ho Salcedo (coord.), op. cit., nota 4, p. 133. La vía de creación de los tribunales para la ex-Yugosiavia y Ruanda tiene "las ventajas de ser rápida e inmediatamente efectiva", pero "no es menos cierto que también genera importantes críticas... A nuestro juicio, las más importantes son tres: una justicia selectiva, una dependencia financiera y temporal y una base jurídica incierta". Zafra Espinosa de los Monteros, "El establecimiento convencional de la Corte Penal Internacional...". en Carrillo Salcedo (coord.), op. cit., nota 4, p. 168.

34 El artículo 9o. del Estatuto del Tribunal para la ex-Yugoslavia señala, bajo el epígrafe de "Jurisdicción concurrente": “1. El Tribunal Internacional y los tribunales nacionales tendrán jurisdicción concurrente para enjuiciar a las personas que hayan cometido violaciones graves del derecho internacional humanitario en el territorio de la ex-Yugoslavia a partir del 10. de enero de 1991. 2. El Tribunal Internacional tendrá primacía respecto de los tribunales nacionales. En cualquier etapa del procedimiento, el Tribunal Internacional podrá pedir oficialmente a los tribunales nacionales que convengan en la competencia del Tribunal Internacional de conformidad con el presente estatuto y con las normas sobre procedimiento y prueba del Tribunal Internacional".

35 Cfr. García Ramírez, Sergio, Los derechos humanos y la jurisdicción.... cit., nota 6, p. 81.

36 En efecto, "la CPI goza en principio de una cierta posición preeminente o facultad de tutela y supervisión sobre las jurisdicciones penales nacionales, en particular porque el estatuto le reconoce competencia sobre su competencia. De este modo, las jurisdicciones penales nacionales tienen una preferencia lutelada, y la CPI puede deshacer la presunción a favor de esas jurisdicciones penales nacionales". Alcaide Fernández, Joaquín, op. cit., nota 4. pp. 416 y 417.

37 Se trata de un fundamental requisito de admisibilidad en el que se muestra el carácter subsi- 
postulado que proviene de la ordenada relación entre los Estados al dirimir cuestiones que susciten sus ciudadanos. Eso mismo ha hecho, en su propio espacio y con sus propios procedimientos, el otro convenio de Roma, el Estatuto de 1998. Hay un punto de confianza en este instrumento del nuevo orden internacional: confianza en que los Estados harán lo que deban, a sabiendas de que deben hacer lo que han aceptado internacionalmente: tutela efectiva de los derechos de los individuos y de los Estados mismos, esto último - sobre todo- cuando exista el delito de agresión en el que siguen trabajando los órganos del sistema penal internacional. ${ }^{38}$

Las ventajas de la complementariedad radican, a mi juicio, en que: a) Es un espacio de convergencia y conciliación entre el concepto de soberanía y el concepto de operación y salvaguarda de un orden jurídico internacional; b) No desplaza, excluye o absorbe las atribuciones, obligaciones y facultades originales del Estado nacional, que tiene a salvo su potestad de regular e intervenir en primer término; y c) No desconoce el desarrollo del orden jurídico en su conjunto, que acepta y convoca un papel relevante del sistema internacional en forma subsidiaria y segura como segundo nivel de garantía. ${ }^{39}$ Evidentemente, la operación natural, debida y eficaz del principio de complementariedad supone la existencia amplia y suficiente de reglas, mecanismos y procedimientos internos que le permitan operar.

En este punto es preciso considerar algunos aspectos de la situación que guardan la corte y su sistema de derecho penal internacional ante los

diario, no principal, de la jurisdicción internacional con respecto a la nacional, como es corriente en el derecho internacional. Así, la Convención Americana sobre Derechos Humanos dispone que para que una petición o comunicación sea admitida por la comisión y se inicie, por lo mismo, el procedimiento ante el sistema tutelar interamericano, se requiere, entre otras cosas, "que se hayan interpuesto y agotado los recursos de jurisdicción interna, conforme a los principios del derecho internacional generalmente reconocidos" (artículo 46.1, a). Bajo la Convención de Salvaguardia de los Derechos del Hombre y las Libertades Fundamentales, el agotamiento de recursos internos se prevé en las condiciones de admisibilidad reguladas por el artículo 35 .

38 En su primera sesión, la Asamblea de los Estados Partes de la CPI resolvió la creación de un Grupo de Trabajo sobre el crimen de agresión, abierto a todos los Estados miembros de las Naciones Unidas o miembros de las agencias especializadas o de la Agencia Internacional de Energía Atómica, que dará cuenta de su propuesta a la asamblea, para los fines de la Conferencia de Revisión prevista en el estatuto. Cfr. Resolución ICC-ASP/1/Res.1, en Assembly of States Parties to the Rome Statute of the International Criminal Court, First session, Nueva York, 3-10 de septiembre de 2002, Official Records, $/ C C-A S P / / / 3$, p. 328.

39 Cfr. Garcia Ramirez, Sergio, La Corte Penal Internacional, 1a. reimp., México, Instituto Nacional de Ciencias Penales, 2002, p. 38. 
Estados, asunto que ha generado las más vivas discusiones. No me refiero tanto a la costumbre internacional y al jus cogens -recogidos en el estatuto-, que se han formado y tienen su propio ámbito de operación independientemente de la corte, sino a lo que concierne directa y específicamente al nuevo derecho asentado en ese ordenamiento. Aquí vienen a colación, una vez más, los principios sobre el desempeño de la jurisdicción penal a los que antes me referí.

En principio, el estatuto -habida cuenta de su naturaleza como tratado internacional-crea obligaciones para los Estados que lo han ratificado $^{40}$ y para aquellos otros que, sin haberlo hecho, convienen con la corte en algunos extremos de jurisdicción o colaboración. ${ }^{41}$ En ambos casos existe, pues, la admisión de un compromiso por parte del Estado. Empero, el tema de la responsabilidad que constituye la esencia del estatuto no concierne a la responsabilidad de los Estados -como ocurre, por otra parte, en el sistema internacional de los derechos humanos y que se ha querido depositar, además, en un instrumento internacional一 ${ }^{42}$ sino de los individuos; a éstos se dirigen las prohibiciones implícitas en los tipos penales, se somete a juicio y se aplican las penas. ${ }^{43}$ La posibilidad de enjuiciar a los ciudadanos de un Estado no parte, sin el consentimiento de éste, "existe en la actualidad en virtud del derecho internacional general y concuerda con la práctica estatal establecida". ${ }^{44}$ En todo caso, esta ha

40 Artículo 12.1: "El Estado que pase a ser parte en el presente estatuto acepta por ello la competencia de la corte respecto de los crímenes a que se refiere el artículo 5o." (genocidio, crímenes de lesa humanidad, crimenes de guerra y agresión). Debieron considerarse expresamente los delitos contra la administración de justicia (artículo 70).

41 El artículo 34 de la Convención de Viena sobre el Derecho de los Tratados puntualiza: "Un tratado no crea obligaciones ni derechos para un tercer Estado sin su consentimiento". El artículo 35 se refiere a las obligaciones para terceros Estados, "si las partes en el tratado tienen la intención de que tal disposición sea el medio de crear la obiigación y si el tercer Estado acepta expresamente por escrito esa obligación". El Estatuto de Roma se refiere a la vinculación de la corte con Estados que no son partes en aquél: artículos 12.3, 97.5 y 93.10.

42 Me refiero al Proyecto de Artículos sobre Responsabilidad de los Estados, de la Comisión de Derecho Internacional, de 1996, cuyo artículo 10. señala que "todo hecho internacionalmente ilícito de un Estado da lugar a la responsabilidad internacional de éste". El artículo 3o. precisa que existe un hecho internacionalmente ilícito de un Estado cuando: "a) Un comportamiento consistente en una acción u omisión es atribuible según el derecho internacional al Estado; y b) Ese comportamiento constituye una violación de una obligación internacional del Estado".

43 Cfr. Ambos, Kai, "Responsabilidad penal individual en el derecho penal supranacional", en varios, Nuevo derecho penal internacional, México, Instituto Nacional de Ciencias Penales, 2002, pp. 339 y ss.

44 Márquez Carrasco, María del Carmen, "Alcance de la jurisdicción de la Corte Penal Internacional: jurisdicción universal o nexos jurisdiccionales aplicables", en Carrillo Salcedo (coord.), op. cit., nota 4, p. 376. La autora toma como ejemplos los tratados de derechos humanos y derecho internacional humanitario. 
sido uno de los puntos más intensamente debatidos, antes de Roma, durante la conferencia y después de ella. ${ }^{45}$

En este orden de consideraciones conviene subrayar que la obligación estatal de penalizar - lo cual abarca tipificación, investigación, procesamiento, condena y ejecución- las conductas que violen gravemente los derechos humanos, tiene una fuente doble: nacional, por una parte; internacional ${ }^{46}$ por la otra. Ese deber del Estado se deduce de las Constituciones nacionales, que fijan -con diversa técnica- los bienes tutelables y obligan a protegerlos, y de las declaraciones y tratados internacionales, que anuncian derechos individuales y obligaciones estatales de protección. ${ }^{47}$ Sobre este cimiento se construye la legislación penal nacional y la regulación penal internacional.

Los Estados que no disponen instrumentos penales para la tutela de los derechos, o que no proveen al eficaz desempeño de esos instrumentos, violan deberes e incurren en responsabilidad internacional -conforme al derecho internacional de los derechos humanos-, que se define en una sentencia o en sucesivas resoluciones con ingredientes declarativos y condenatorios. ${ }^{48}$ En la experiencia interamericana, es frecuente la sentencia -en el marco de las reparaciones - a investigar los delitos cometidos, procesar a sus autores y dictar las condenas correspondientes. ${ }^{49} \mathrm{Nada}$ de

45 Durante la Conferencia de Roma, el 9 de julio, la delegación de los Estados Unidos dejó constancia de una interrogante y una posición: "El interrogante fundamental es este: ¿tendrá la corte competencia para procesar los oficiales y el personal de un gobierno sin que el gobierno se haya hecho parte del tratado o de alguna otra manera se haya sometido a la competencia de la corte? Esta es una modalidad de la competencia extraterritorial que podría ser bastante heterodoxa en la práctica de los tratados, aplicar el régimen de un tratado a un país sin su consentimiento". Bergsmo, "El régimen de la competencia de la Corte Penal Internacional (parte II, artículos 11 a 19)", trad. de Óscar Julián Guerrero P., en Ambos y Guerrero (comps.), El Estatuto de Roma de la Corte Penal Internacional, Bogotá, Colombia, Universidad Externado de Colombia, 1999, p. 188.

46 Cfr. Ambos, Kai, "Deberes de penalización en caso de violaciones graves a los derechos humanos", en varios, op. cit., pp. 37 y ss.

47 Es asi que bajo la Convención Americana de Derechos Humanos, los Estados partes se comprometen a respetar derechos y garantizar su libre y pleno ejercicio a todas las personas (artículo 1o.); si ese ejercicio no estuviese garantizado por disposiciones legislativas o de otro carácter, el Estado deberá adoptar las medidas necesarias para tal fin (artículo 2o.). Evidentemente, la formulación de tipos penales obedece al proposito de crear un medio de control adicional -el "último", sostienen las corrientes del derecho penal democrático- para la protección de bienes jurídicos que son el contenido de los derechos de las personas: vida, libertad, integridad, patrimonio, etcétera.

48 Cfr. García Ramircz, Sergio, Los derechos humanos y la jurisdicción..., cit., nota 6, p. 146.

49 Cfr. García Ramirez, Sergio, "Las reparaciones en el sistema interamericano de protección de los derechos humanos", Estudios juridicos, México, UNAM, Instituto de Investigaciones Juridicas, 2000 , pp. 438 y ss. 
esto puede ser despachado "como mera formalidad",, 50 sin verdadera consistencia —que sería una patente de impunidad..$^{51}$

Con la mirada puesta en los principios jurisdiccionales tradicionales, en el estado actual del derecho y las relaciones internacionales y en la necesidad de lograr un consenso en Roma - para favorecer el punto de partida de esta nueva etapa del derecho penal internacional, que no es también, por fuerza, su punto de llegada- el estatuto articuló la jurisdiccionalidad de la corte bajo el sencillo epígrafe del artículo 12, que no expone la relevancia de la materia que regula: "Condiciones previas para el ejercicio de la competencia".

Como era de esperarse, este asunto mereció la más alta prioridad en Roma: eje del quehacer jurisdiccional de la futura corte y expresión del "tipo de jurisdicción" que se pretendía - a partir de posiciones encontradas-, "se convirtió en el problema más importante, el de mayor dificultad política y, en consecuencia, el que generó mayores tensiones dentro de todo el conjunto de problemas que constituyeron materia de las negociaciones: para decirlo en breve, 'la cuestión de las cuestiones' del proyecto de la corte". 52

Para el ejercicio de la competencia de la CPI se toman en cuenta dos elementos fundamentales: el carácter de los Estados como partes o no del estatuto, y la instancia de la que procede el caso llevado primero ante el fiscal y juzgado más tarde por el tribunal. Estos datos se proyectan, a su vez, en dos supuestos, uno con base "consensual" y otro con fundamento "constitucional", 53 además de la excepción contenida en el artículo 124.

50 La "investigación de los hechos y la sanción de las personas responsables... es una obligación que corresponde al Estado siempre que haya ocurrido una violación de los derechos humanos y esa obligación debe ser cumplida seriamente y no como mera formalidad". CIDH, Caso El Amparo. Reparaciones (articulo 63.1 Convención Americana sobre Derechos Humanos). Sentencia de 14 de septiembre de 1996, serie C, núm. 28, párr. 61.

51 La Corte Interamericana de Derechos Humanos ha recogido el concepto de impunidad como "la falta en su conjunto de investigación, persecución, captura, enjuiciamiento y condena de los responsables de las violaciones de los derechos protegidos por la Convención Americana, toda vez que el Estađo tiene la obligación de combatir tal situación por todos los medios legales disponibles, ya que la impunidad propicia la repetición crónica de las violaciones de derechos humanos y la total indefensión de las víctimas y de sus familiares". Caso Paniagua Morales y otros. Sentencia de 8 de marzo de 1998, serie C, núm. 37, pfo. 173.

52 Kaul, Hans Peter, "La Corte Penal Internacional: la lucha por su competencia y su alcance", trad. de Óscar Juiián Guerrero, en Ambos y Guerrero (comps.), op. cit., nota 45, p. 214. El autor refiere las negociaciones sobre esta materia y analiza las diversas alternativas examinadas hasta llegar a la solución definitiva, prácticamente en el último momento de la conferencia: régimen opt in-opt out, régimen del consentimiento del Estado y competencia automática, pp. 217 y ss.

53 Márquez Carrasco, María del Carmen, op. cit., nota 44, p. 367. 
En primer término, la corte puede ejercer sus atribuciones jurisdiccionales en relación con crímenes perpetrados en el territorio de un Estado ${ }^{54}$ o por nacionales de éste, cuando se trate de Estado parte en el estatuto o así lo consienta explícitamente un Estado que no sea parte en aquél (artículo 12.2.a y b, en relación con el artículo 13.a y c). ${ }^{55}$ Esta categoría se informa, como es evidente, por los conceptos de territorialidad y nacionalidad activa, que son la base de la jurisdicción interna, trasladada a la CPI por el Estatuto de Roma en la forma y con las modalidades que éste contiene. No omito mencionar el supuesto de la admisibilidad de asuntos específicos por acuerdo con un Estado que no es parte en el estatuto. No se trata de una novedad del estatuto: esta "fórmula de excepcionalidad" ya se aplica en otros sistemas. ${ }^{56}$ Lo que sucede es que en esta hipótesis se actualiza una especie de jurisdicción $a d$-hoc, históricamente anterior al ordenamiento de Roma. Por supuesto, puede verse desde diversas perspectivas: un paso atrás en el régimen general o un paso adelante hacia la plenitud universal de aquél.

En segundo término, la corte puede ejercer aquellas atribuciones en relación con los crímenes previstos en el estatuto, independientemente del lugar en el que se cometieron y de la nacionalidad de la persona que los realizó, cuando sea el Consejo de Seguridad de Naciones Unidas quien haga la remisión del caso (artículo 12.2, párrafo inicial, a contrario sensu, en relación con el artículo 13.b). Esta categoría extiende considerablemente la potestad del sistema internacional de justicia penal y lleva a mayor profundidad el principio de jurisdicción universal, pero entrega a una sola instancia, no nacional, la "palanca" para que el sistema opere con esa extensión y esa profundidad. ${ }^{57}$

$54 \mathrm{O}$ bien, extensivamente, a bordo de un buque o una aeronave. En estos casos se considera al Estado de matrícula del buque o aeronave (artículo 12.1.2).

55 En la Conferencia de Roma, muchos Estados propusieron conceder a la corte la misma jurisdicción universal que ellos tienen prevista en sus leyes internas respecto de genocidio, crímenes de lesa humanidad y crímenes de guerra. "Sin embargo, debido a un acuerdo alcanzado en el último momento con objeto de persuadir a ciertos Estados para que no se opusieran a la corte, el Estatuto de Roma omite tal jurisdicción si el fiscal actúa a partir de información de fuentes que no sean el Consejo de Seguridad". Márquez Carrasco, Maria del Carmen, op. cit., nota 44, pp. 372 y 373.

56 Así, por ejemplo, conforme al sistema de cláusula facultativa de la Convención Americana sobre Derechos Humanos. En ésta, se acepta la admisión de competencia de la Corte Interamericana "para casos específicos" (artículo 62.2 de dicha Convención).

57 La facultad concedida al consejo fue controvertida antes de la Conferencia de Roma y durante esta misma. Algunos Estados consideraron que "las remisiones provenientes del (Consejo de Seguridad), por tener éste un carácter político, tendrían una connotación de esa naturaleza". Los defensores de esa facultad tuvieron en cuenta la pertinencia de que el consejo "se sirviera de la Corte Penal 
En este marco es posible someter a la jurisdicción internacional hechos realizados en el territorio de un Estado que no sea parte en el estatuto, o someter a juicio a una persona cuya nacionalidad no corresponda a un Estado parte. En estos casos las atribuciones del Consejo de Seguridad, como vigilante de la paz y la seguridad internacionales, vienen en apoyo de la jurisdicción de la corte, que se vería detenida por el artículo 12.2 del estatuto. Algunos estudiosos señalan que las condiciones previas para el ejercicio de la jurisdicción hacen suponer que "la CPI será durante años principalmente una 'criatura' del Consejo de Seguridad". ${ }^{58}$ También se ha observado que "la considerable responsabilidad para poner en vigencia de manera efectiva el derecho penal internacional todavía descansa en los miembros permanentes del Consejo de Seguridad". ${ }^{59}$ Empero, también es cierto que las condiciones para que el consejo suspenda el procedimiento resultan "muy onerosas": lo colocan "en la mira de la comunidad internacional". 60

Un régimen de remisión libre a la Corte Penal Internacional podría soslayar el principio de complementariedad si operase sin control o correctivo. Desde luego, el correctivo principal, que es al mismo tiempo reconocimiento de la potestad original y preferente del Estado, reside en la posibilidad de que éste requiera al fiscal, una vez que se ha iniciado un procedimiento, para que remita el caso a la justicia interna, ${ }^{61}$ si ella posee

Internacional para conocer de los graves crimenes contemplados en el (estatuto), en vez de crear nuevos tribunales, como lo hiciera para la ex-Yugoslavia y Rwanda". Quezada, Alejandra, op. cit., nota 3, p. 101 .

58 "Y si se ejerce el veto o falta voluntad política en el consejo, la corte no podrá actuar". Márquez Carrasco, María del Carmen, op. cit., nota 44, pp. 379 y 380.

59 Bergsmo, op. cit., nota 45, p. 201. La potestad que el estatuto confiere al Consejo de Seguridad fue enérgicamente custionada en Roma por las delegaciones de la India y México. Cfr. Bergsmo, op. cit, en esta misma nota, p. 191, y González Gálvez, Sergio, La Corte Penal Internacional, el uso de las armas convencionales en caso de conflicto armado y la injerencia con fines humanitarios. Tres temas básicos del derecho internacional humanitario, México, Secretaría de la Defensa Nacional, 2000 , pp. 9 y ss.

60 Tello, Manuel, "El proceso de formación del Estatuto de Roma", en Guevara B., José A. y Valdés Riveroll, Mariana (comps.), La Corte Penal Internacional (Ensayos para la ratificación e implementación de su estatuto), México, Universidad Iberoamericana-Secretaría de Relaciones Exteriores, 2002, p. 17.

$61 \mathrm{El}$ asunto es inadmisible ante la corte, en principio y salvo las excepciones que el estatuto dispone, cuando "sea objeto de una investigación o enjuiciamiento en el Estado que tiene jurisdicción sobre él", o haya sido objeto de dicha investigación por parte del propio Estado o el inculpado haya sido ya enjuiciado en éste por el delito supuestamente cometido (artículo 17, l a, b y c). Puede impugnar la admisibilidad de una causa o la competencia de la corte "el Estado que tenga jurisdicción en la causa porque está investigándola o enjuiciándola o lo ha hecho antes" (artículo 19.2.b). 
las atribuciones necesarias para el enjuiciamiento, como ocurriría en la hipótesis de que el inculpado fuese nacional de dicho Estado. Obviamente, el mismo Estado puede también asumir el conocimiento del caso antes de que lo haga la jurisdicción internacional. Esta posibilidad, siempre abierta -y, en principio, la más probable, conveniente y deseable- debiera desalentar los argumentos de algunos opositores al estatuto. ${ }^{62}$ Veamos ahora otros aspectos de la cuestión, concernientes a la actuación del fiscal y a las atribuciones de la corte en el rubro de la admisibilidad. ${ }^{63}$

La complementariedad se analiza y define cuando el estatuto desarrolla la intervención de la corte — sea para investigar, sea para enjuiciarpor encima o a pesar de la jurisdicción del Estado competente. Aquí se plantea una confrontación en funciones indagatorias, persecutorias y jurisdiccionales, que no se resuelve necesariamente en forma desfavorable para la jurisdicción del Estado. En síntesis, si hay una jurisdicción nacional dispuesta, capaz y suficiente, el asunto debe quedar a su cargo; de lo contrario, la investigación, el juicio y la sentencia incumben a la jurisdicción internacional. ${ }^{64}$ Esto sucede en la hipótesis del fundamental artículo $17,{ }^{65}$ que analiza la materia bajo el epígrafe puntual de "Cuestiones de admisibilidad": 66 que el Estado con jurisdicción original o natural "no esté dispuesto a llevar a cabo la investigación o el enjuiciamiento o no pueda realmente hacerlo"' (artículo 17.1. a y b).

Es la admisibilidad, no la competencia, lo que aquí se examina: si el Estado actúa, el caso devendrá inadmisible ante la Corte Penal Internacional. De lo contrario, ésta se ocupará del caso admisible y admitido. El punto interesa también al tema de la cosa juzgada y la regla ne bis in

62 Anello maneja este argumento con apoyo normativo y doctrinal, al examinar la posición estadounidense ante el Estatuto de Roma. Cfr. Anello, Carolina Susana, op. cit., nota 29, p. 37.

63 La parte II del tratado de Roma, alusiva a competencia, admisibilidad y derecho aplicable, ha sido calificada como el "corazón" del estatuto. Cfr. Quezada, Alejandra, op. cit, nota 3, p. 92, quien cita a Mahnoush H. Arsanjani.

64 En opinión de Kai Ambos, "debe admitirse una falta de voluntad de persecución penal cuando un determinado Estado incorpora un procedimiento sólo aparente, para sustraer a la persona interesada de la persecución penal; cuando se verifique una dilación procesal incompatible con una intención de persecución penal; o cuando el proceso no se sustancie de manera independiente o imparcial. La jurisdicción nacional será incapaz para la persecución penal cuando, con base en su colapso total o esencial, no consigue hacer comparecer al acusado o proporcionar los medios de prueba necesarios" (énfasis del autor). Ambos, Kai, "Sobre el fundamento jurídico de la Corte Penal Internacional. Un análisis del Estatuto de Roma", trad. de Miguel Ángel Iglesias Río y Lucía Martínez Garay, en Ambos y Guerrero (comps.), op. cit., nota 45, p. 112.

$65 Y$ sus conexiones con los artículos que regulan el procedimiento correspondiente: 18 y 19 , además de su relación con otro precepto de gran importancia: artículo 20 , en torno a la cosa juzgada.

66 Cfr. Alcaide Fernández, Joaquín, op. cit., nota 4, pp. 385 y ss. 
idem, que el estatuto coloca, con toda intención, en la parte II, "De la competencia, la admisibilidad y el derecho aplicable", y no, como también pudo ocurrir - habida cuenta de la jerarquía político-jurídica de esta regla-, en la parte III, "De los principios generales de derecho penal".

Hay medios para exigir y alcanzar las consecuencias de la complementariedad. Se concreta en un derecho del Estado que asume diversas expresiones según el momento y la forma en que se actualice. Por una parte, existe la posibilidad de: a) Solicitar al fiscal se inhiba de proseguir la investigación que ya adelanta un Estado, ${ }^{67} \mathrm{o}$ bien, $b$ ) Impugnar la competencia de la corte o la admisibilidad de la causa (al amparo del artículo 17). ${ }^{68}$ Por la otra, es igualmente posible que el Estado recupere —con diverso fundamento, que infra analizaré en detalle-el ejercicio de su competencia. En el primer supuesto, el Estado sale inmediatamente al paso de la actuación de la corte, mediante la reclamación correspondiente.

En la encrucijada entre la jurisdicción nacional y la internacional se hallan la disposición de juzgar que tenga el Estado competente y la capacidad de que disponga para hacerlo, a la que me he referido anteriormente. Aquello se establece con la mirada puesta en el propósito con el que se siga el proceso jurisdiccional interno y la intención de hacer justicia, ${ }^{69}$ entre otros datos sobre independencia, imparcialidad y garantías (artículo 20.3). Pero no siempre será fácil desentrañar, con certeza, los propósitos y las intenciones. ${ }^{70}$ La Corte Penal Internacional, que resuelve sobre la admisibilidad y acerca de su propia competencia -tiene la compétence de la compétence; o de otra manera, es "dueña de su competencia","1 porque de lo contrario vendría por tierra todo el orden penal internacio-

67 Esta petición se regula en el articulo 20., sujeta a plazo y pendiente de resolución final, si surge oposición, por parte de la Sala de Cuestiones Preliminares. El fiscal puede reexaminar la inhibjción al cabo de seis meses "o cuando se haya producido un cambio significativo de circunstancias en vista de que el Estado no está dispuesto a llevar a cabo la investigación o no puede realmente hacer10" (párrafos 2 y 3 ).

68 Pueden impugnar la admisibilidad de la causa, en función del artículo 17, o la competencia de la corte, tanto el acusado como "el Estado que tenga jurisdicción en la causa porque está investigándola o enjuiciándola" y "el Estado cuya aceptación se requiera de conformidad con el artículo 12 " (artículo 19.2). Desde luego, la corte puede analizar de oficio la competencia y la admisibilidad, y el fiscal puede promover cuestiones de esta naturaleza ante el tribunal (artículo 12.1 y 3 ).

69 El artículo 20.3 habla del "propósito de sustraer al acusado de su responsabilidad penai por crimenes de la competencia de la corte" (a), y de un proceso instruido de manera que "fuere incompatible con la intención de someter a la persona a la acción de la justicia" (b).

70 El propósito de sustraer "implica la evaluación de situaciones objetivas, no necesariamente jurídicas". Comisión Andina de Juristas, op. cit., nota 5, p. 148.

71 Márquezz Carrasco, María del Carmen, op. cit., nota 44, p. 367. Asimismo, cfr. Alcaide Fernández, Joaquín, op. cit, nota 4, p. 417. 
nal, también resuelve, consecuentemente, acerca de la competencia, la voluntad y la aptitud del Estado que podría reclamar el conocimiento, o que efectivamente lo demanda.

Dicha potestad de "juicio sobre la justicia", como sustento para el "juicio sobre la responsabilidad penal", en su caso, se halla en la lógica misma del tratado, pero también en los términos de sus preceptos. ${ }^{72}$ Esta es una tierra movediza, por la que se transitará con dificultad. Quienes han negado y deplorado que el estatuto recoja verdaderamente el principio de complementariedad, suelen referirse a la posibilidad de que la corte se sobreponga a la jurisdicción nacional con facilidad, sin que para ello se acrediten factores que realmente lo justifiquen. ${ }^{73}$ Por cierto, esta misma opinión sostienen los partidarios de la jurisdicción penal internacional, aunque, claro está, desde una perspectiva diferente. ${ }^{74}$ En el juicio sobre la justicia habrá $-\mathrm{y}$ ha habido: lo muestran las experiencias de la ex-Yugoslavia y Ruanda - casos de obvia solución, pero también los habrá de tratamiento difícil, incierto, opinable.

Por otra parte $-y$ sin perjuicio del señalamiento expreso del estatuto, que se refiere a todas las hipótesis de inoperancia de la justicia nacional en asuntos concretos-, lo probable es que se deba profundizar el análisis en la individualidad de los casos en que no haya disposición de actuar; en los otros, relacionados con el "colapso total o sustancial de (la) administración nacional de justicia o el hecho de que (se) carece de ella" (artículo 17.3), la consideración de la CPI debe extenderse hacia el conjunto del sistema de justicia: obviamente, la incapacidad de éste en general traerá consigo - aunque no inexorablemente; puede haber algún espacio para la apreciación casuística- la incapacidad de actuar en el caso individual. Los críticos de estas soluciones preferirían fórmulas más precisas - como

72 Así, en los párrafos 2 y 3 del articulo 17 , que señalan las circunstancias que la corte "examinará" a "fin de determinar si hay o no disposición a actuar en un asunto determinado" (párrafo 2) o "la incapacidad para investigar o enjuiciar un asunto determinado".

73 En este sentido, la posición estadounidense. Cfr. Gurulè, Jimmy, "United States opposition to the 1998 Rome Statute stablishing an International Criminal Court: Is the Court's jurisdiction truly complementary to national criminal jurisdictions?", Cornell International Law Journal, vol. 35, núm. 1 , noviembre de 2001 -febrero de 2002 , p. 44.

74 El examen que hace la CPI sobre la gestión de la justicia nacional es "una diáfana verificación de la relativa fuerza que registra la prioridad asignada al Estado interviniente; más bien pareciera fortalecerse el principio de autonomía frente al de complementariedad, criterio que, no dudamos, debiera ser acogido favorablemente en cuanto contribuye a consolidar la independencia del tribunal". Baigún, David, "El Estatuto de Roma y la responsabilidad penal de las personas jurídicas", en varios, op. cit., nota 9 , p. 90 . 
garantía para la justicia nacional一 para que la jurisdicción internacional desplace a la interna: así, "mala fe y evidente error judicial". ${ }^{75}$

En los casos de frontera, ¿cómo explorar y afirmar el "propósito de sustraer a la persona de que se trate de su responsabilidad penal por crímenes de la competencia de la corte", según indica el artículo 17.2.a, o la "¿Intención de someter a la persona a la acción de la justicia, como señala el mismo precepto en el inciso b? ¿Cómo se precisará que existe una "demora injustificada en el juicio" - -tema del artículo 17.2.b-, habida cuenta de que la tardanza en resolver ha sido y es un mal endémico de la justicia, acaso el más extendido y notorio, como podría acreditarlo la experiencia de la Corte Europea de Derechos Humanos? ¿En qué fundamento seguro descansará la idea de que un proceso "no haya sido o no esté siendo sustanciado de manera independiente o imparcial", y en cambio lo haya sido o lo esté siendo de manera "incompatible - dice el artículo 17.2.c, que guarda relación con el 20-con la intención de hacer comparecer a la persona de que se trate ante la justicia'?

\section{LEY NACIONAL MÁS BENIGNA}

Surgirá materia para la deliberación —que conduzca a reglas generales y a soluciones individuales- cuando la ley nacional resulte ser, por motivos no reprochables, más "benigna" que la internacional, sin que esto implique necesariamente una intención de impunidad por parte del legislador doméstico, y mucho menos del juez. Por ejemplo - y sin perjuicio de lo que señalaré infra, al referirme a los elementos de los crímenes-, en el estatuto la intención y el conocimiento que integran el dolo se refieren sólo a los elementos materiales del crimen. ¿Qué sucederá si la ley nacional exige más que eso: conocimiento de otros elementos del crimen? ${ }^{76}$

75 Cfr. Gurulé, Jimmy, op. cit., nota 73, p. 44.

76 Independientemente de la apreciación que merezca la técnica adoptada, existen diferencias en la regulación positiva que se proyectan sobre el proceso y la sentencia. Tómese como ejemplo el caso de la legislación mexicana. El Código Penal Federal, con una fórmula de muy reciente incorporación, declara: "Obra dolosamente el que, conociendo los elementos del tipo penal, o previniendo como posible el resultado típico, quiere o acepta la realización del hecho descrito por la ley" (artículo 9o.). El Código Penal para el Distrito Federal, de elaboración aún más reciente (2002), señala al respecto: "Obra dolosamente el que, conociendo los elementos objetivos del hecho típico de que se trate, o previendo como posible el resultado típico, quiere o acepta su realización" (énfasis agregado). Enrique Díaz Aranda explica que "el conocimiento de quien obra dolosamente gira en tomo a dos elementos del tipo objetivo: descriptivos y normativos". Díaz Aranda, Enrique, Dolo. Causalismo-fina- 
La falta de ese conocimiento más completo eliminaría el dolo conforme a la ley doméstica y traería consigo una resolución final distinta de la que sobrevendría en el foro internacional. Empero, aquí no se actualizan a fortiori los supuestos de los que depende la intervención de la CPI con desplazamiento de la jurisdicción interna: propósito de sustraer al inculpado de su responsabilidad penal, falta de independencia o imparcialidad o colapso del sistema de justicia. Creo que esto contribuye a reflexionar sobre la improcedencia de exigir la identidad completa entre la legislación nacional y la internacional, a partir de ésta.

También aparecerán cuestiones inquietantes, controvertibles, cuando los órganos de la justicia nacional —e incluso los encargados de la persecución o de la ejecución-, comprometidos con un proceso de reconciliación nacional, apliquen un trato benévolo al inculpado. Se actualizará el dilema entre justicia y paz que han invocado los adversarios de la jurisdicción universal. ${ }^{77}$ Difícilmente podría sustraerse la $\mathrm{CPI}$ al conocimiento de esos casos, si la benevolencia nacional choca fuertemente con las reglas y principios del Estatuto de Roma, pero tampoco podría excluir de su horizonte la aplicabilidad — sea para admitirla, sea para desecharla- de su propio examen de oportunidad, que inevitablemente trae el dato político al escenario de la consideración jurídica.

\section{NE BIS IN IDEM}

Me referí al principio ne bis in idem ${ }^{78}$ que ha estado en el centro del debate en muchos escenarios nacionales, aunque probablemente menos que otros temas a propósito de la corte. En esa regla que fue de oro reside la seguridad jurídica, no siempre la justicia. La cosa juzgada, que afianza el ne bis in idem, posee cierta relatividad donde debiera tener una fuerza absoluta: el enjuiciamiento penal. No hay cosa juzgada, en efecto - salvo

lismo-funcionalismo y la reforma penal en México, 2a. ed., México, Porrúa, 2000, p. 118. "Para definir la voluntad dolosa deben tomarse como base los elementos objetivos del tipo". Islas de González Mariscal, Olga, Análisis lógico de los delitos contra la vida, 4a. ed., México, Trillas, 1998, p. 47.

77 El dilema último al que se enfrenta un estadista —dice Kissinger-- es hallar un equilibrio "entre los valores y los intereses y, ocasionalmente, entre la paz y la justicia". Does America need a foreign policy? Toward a Diplomacy for the 2/st. Century, Nueva York, Touchstone, 2001, p. 286.

78 Cfr. Guevara B., José A., “La Corte Penal Internacional podría juzgar a una persona que hubiere sido condenada por un tribunal nacional de alguno de los Estados parte del estatuto?', en Guevara y Valdés (comps.), La Corte Penal Internacional..., cit., nota 60, pp. 119 y ss. 
algunas leyes nacionales - cuando la sentencia penal fue condenatoria: cabe la revisión, que no es una ulterior instancia, pero sí un nuevo juicio. Convengo, sin embargo, en que este no es el problema. En el derecho actual hay excepciones al ne bis in idem, claramente establecidas en el derecho regional europeo: así, el artículo 35 del Convenio sobre Transmisión de Procedimientos en Materia Penal, ${ }^{79}$ y el 4.1 del Protocolo 7, del 22 de noviembre de 1984, del Convenio sobre Derechos y Libertades Fundamentales. ${ }^{80}$

En la meditación sobre este asunto se advierte que la regla ne bis in idem atenta a la seguridad jurídica, supone la actuación del órgano que naturalmente garantiza aquélla: un tribunal "confiable" que realice un proceso "verdadero". Esto no significa, claro está, tribunal perfecto, infalible, pero supone que el órgano llamado a hacer justicia —para que la regla de seguridad tenga un cimiento superior y no sea simple consecuencia de un dictum formalmente intocable - efectivamente tiene la intención de hacerla, dispone de las condiciones para ello y actúa con ese propósito. Si esto no sucede, el tribunal dejaría de ser, propiamente, garantía de seguridad jurídica y generaría inseguridad general. De aquí que no deban prevalecer sus resoluciones aquejadas de fraude, torpeza o debilidad. ${ }^{81}$

Este tema colinda con otros de raíz semejante, aunque de institución separada: por ejemplo, la operación de las "autoamnistías" que han desechado la jurisprudencia de la Corte Interamericana de Derechos Humanos, ${ }^{82}$ el Acuerdo entre Naciones Unidas y el Gobierno de Sierra Leo-

79 Ese precepto no obliga a los Estados contratantes, salvo al que solicitó la instrucción del procedimiento, "a reconocer el efecto de ne bis in idem si el hecho que haya dado lugar a la sentencia hubiese sido cometido contra una persona, una institución o una propiedad con carácter público o si la persona contra la que se pronunció la sentencia tenía carácter público en ese Estado".

80 El párrafo 1 del artículo 70. del Protocolo establece el ne bis in idem; el párrafo 2 indica: "Lo dispuesto en el párrafo anterior no obsta a la reapertura del proceso, conforme a la ley y al procedimiento penal del Estado interesado, cuando hechos nuevos o revelaciones nuevas, o cuando un vicio esencial en el procedimiento anterior pudieran afectar a la sentencia dictada".

81 En su examen sobre la firmeza de la cosa juzgada nacional y la aplicabilidad del principio ne bis in idem, José A. Guevara apunta: "La Corte Penal Internacional no podrá juzgar a ninguna persona que hubiere sido juzgada de buena fe y de manera imparcial e independiente por un tribunal nacional de alguno de los Estados parte (en el Estatuto de Roma), por los mismos delitos”. "¿La Corte Penal Internacional podría juzgar a una persona que hubiere sido condenada o absuelta por un tribunal nacional de alguno de los Estados parte del estatuto?", en Guevara y Valdés (comps.), La Corte Penal Internacional..., cit., nota 60, p. 119.

82 Este tribunal se ha pronunciado sobre el punto en varias ocasiones, a saber: Caso Loayza Tamayo. Reparaciones (art. 63.I de la Convención Americana sobre Derechos Humanos). Sentencia de 27 de noviembre de 1998, serie C, núm. 42, pfos. 168 y 170; Caso Castillo Páez. Reparaciones 
na ${ }^{83}$ cuestión que pudiera suscitarse ante la Corte Penal de La Haya ${ }^{84}$ En fin, la preservación a ultranza del ne bis in idem -más allá de los supuestos en los que el propio estatuto lo sostiene- traería la decadencia del sistema de justicia penal internacional, invariablemente frenado por investigaciones o juicios previos, que pudieran ser en fraude de la justicia. Desde luego, habrá que fijar con rigor la relatividad del ne bis in idem ante la justicia internacional; no podría ser argumento para reducir otros principios que no están sujetos a esa relatividad, como la irretroactividad del estatuto.

\section{IMPRESCRIPTIBILIDAD}

El estatuto, que navega en aguas encrespadas, debió enfrentar del mejor modo posible el problema de la prescriptibilidad o imprescriptibilidad de la pretensión punitiva, que también se relaciona estrechamente con la justicia, la seguridad jurídica y la "posibilidad política". El artículo 29 declara, enfáticamente: "Los crímenes de la competencia de la corte no

(art. 63.1 de la Convención Americana sobre Derechos Humanos). Sentencia de 27 de noviembre de 1998, serie C, núm. 43, pfo. 105; Caso Barrios Altos. Sentencia de 14 de marzo de 2001, serie C, núm. 75 , pfos. 41-44. El criterio adoptado en esta última resolución tiene alcance general, según estableció la propia corte en la resolución de interpretación de la sentencia de fondo, el $\mathbf{4}$ de septiembre de 2001. Cfr., asimismo, mi Voto concurrente en la sentencia de reparaciones del Caso Castillo Páez, reiterado en la sentencia de reparaciones del Caso Loayza Tamayo, y nuevamente desarrollado en mi Voto concurrente en la sentencia del Caso Barrios Altos (pfos. 9 y ss.), y mi articulo: "Dos temas de la jurisprudencia interamericana: 'proyecto de vida' y amnistía", Estudios juridicos, cit., nota 49, pp. 363 y ss.

83 En el informe del secretario general al Consejo de Seguridad se puntualiza que "aunque reconocen que la amnistía es un concepto jurídico aceptado y una muestra de paz y reconciliación al final de una guerra civil o de un conflicto armado interno, las Naciones Unidas mantienen sistemáticamente la posición de que la amnistía no puede concederse respecto de crímenes internacionales como el genocidio, los crímenes de lesa humanidad o las infracciones graves del derecho internacional humanitario". Informe del Secretario General sobre el establecimiento de un tribunal especial para Sierra Leona, 4 de octubre de 2000, S/2000/915, p. 5. El artículo 10 del acuerdo señala: "La amnistía concedida a una persona respecto de la cual el Tribunal Especial tenga competencia en relación con uno de los crímenes a que se hace referencia en los articulos 20 . a 4o. del presente estatuto no constituirá un impedimento para el procesamiento".

84 Santiago Corcuera Cabezut estudia y rechaza las que denomina "amnistías de facto", cuya aprobación y aplicación entrañarian violación a los tratados internacionales sobre derechos humanos y acarrearian la responsabilidad internacional del Estado. Corcuera Cabezut, Santiago, "El principio de subsidiariedad de la compctencia de la Corte Penal Internacional", en Guevara y Valdés (comps.), La Corte Penal Internacional..., cit., nota 60, pp. 104 y ss. 
prescribirán". ${ }^{85} \mathrm{El}$ punto suscitó preocupaciones ${ }^{86}$ Existe un convenio internacional sobre la materia que se proyecta sobre los crímenes de guerra y de lesa humanidad; ${ }^{87}$ en relación con éstos, el paso del tiempo no elimina la pretensión punitiva. Lo que se hizo antes de que tuviera vigencia el estatuto puede ser penalmente relevante para diversos fines, pero no para la competencia ratione temporis de la corte. El punto se halla resuelto bajo el rubro nullum crimen sine lege —como cuestión de lege praevia(artículo 22) y, con un emplazamiento discutible, bajo el concepto de la irretroactividad ratione personae (artículo 24). ${ }^{88}$ Sin embargo, la imprescriptibilidad no rige en todos los casos abarcados por la competencia material de la corte: en efecto, opera la prescripción cuando se trata de los delitos contra la administración de justicia (regla 164), que también corresponden a ese ámbito de competencia, sin perjuicio del conocimiento que se reconoce, asimismo, a la justicia nacional.

\section{OPORTUNIDAD CONFORME A LA LEY NACIONAL}

Otro punto de frontera se plantea cuando rige en la ley nacional el principio de oportunidad persecutoria, que también existe en la interna-

85 La escueta expresión no es acertada: obviamente los crímenes no prescriben; lo que prescribe $\longrightarrow$ no- es la pretensión punitiva o la potestad de ejecutar la condena. Así lo han expresado los ordenamientos mexicanos más recientes: el Código Penal para el Distrito Federal, del 2001, se refiere a la prescripción "de la pretensión punitiva" (articulo 108 y otros) y "la potestad para ejecutar las penas y medidas de seguridad" (artículo 109 y otros), en forma consecuente con la denominación general de la materia, que abarca diversas figuras (entre ellas la prescripción): "Extinción de la pretensión punitiva y de la potestad de ejecutar las penas y medidas de seguridad" (título $\mathrm{V}$ del libro primero). El transcurso del tiempo puede $\longrightarrow$ no- impedir que la pretensión prospere o que se ejecute la sentencia condenatoria.

86 El informe del grupo de trabajo expresó una de esas preocupaciones: "La ausencia de limitaciones estatutarias para la corte origina la cuestión referida al principio de complementariedad dado que fa posibilidad de que existan limitaciones estatutarias bajo la ley nacional puede prohibir la acción de las cortes nacionales luego de que expire determinado periodo, mientras que la CPI estaría aún en condiciones de ejercer su jurisdicción". Schabas, "Principios generales de derecho penal", en Ambos y Guerrero (comps.), op. cit., nota 45, p. 301.

87 Convención sobre la Imprescriptibilidad de los Crímenes de Guerra y de los Crímenes de Lesa Humanidad (1968). En la primera hipótesis se recogen los conceptos de Nüremberg, la Asamblea de Naciones Unidas y los Convenios de Ginebra; en la segunda, las resoluciones de la Asamblea General y el convenio sobre genocidio.

88 No se trata, propiamente, de un tema de competencia en razón de la persona, sino en razón del tiempo en el que se realizaron los hechos que serán $\longrightarrow$ serian- susceptibles de conocimiento por parte de la corte. La redacción del artículo 24.1 conduce a hablar, forzadamente, de irretroactividad en razón de la persona: "Nadie será penalmente responsable de conformidad con el presente estatuto por una conducta anterior a su entrada en vigor". 
cional. En varios Estados ha ganado terreno, contra la resistencia que opone todavía el principio de legalidad, la regla de una oportunidad que se aprecia en la investigación - y en tal caso es determinante de cierta conducta del fiscal - o en el juzgamiento. Esta espada de doble filo - disolvente de la justicia o contribuyente a la equidad: he ahí el doble filo-tiene sede en el estatuto a través de conceptos como la gravedad de los hechos, que debe ser suficiente para determinar la intervención de la jurisdicción internacional, o el interés de la justicia, que puede traer consigo una consecuencia posiblemente paradójica: cierre de la investigación o conclusión del proceso. ${ }^{89}$ Pero la misma razón que frena la justicia internacional podría frenar la nacional. El tema suscitará delicadas cuestiones para el funcionamiento de la complementariedad. Ya me he referido a algunas de ellas.

\section{COINCIDENCIA O CONGRUENCIA DE NORMAS}

Para que funcione la complementariedad se necesita coincidencia o, acaso mejor, congruencia de normas, aunque no precisamente identidad, entre los órdenes complementado -el nacional-y complementario - el internacional. De otra suerte operaría, en vez de un régimen de espejos, uno de círculos excéntricos que convertiría la atracción internacional en regla, por deficiencia de la jurisdicción nacional. La coincidencia implica, a mi juicio, sólo posibilidad de que la interna llegue por sí misma al resultado que puede producir la internacional. Así se conjuran los datos - peligros, desde otra óptica- que determinan la admisibilidad de los litigios ante ésta: voluntad de perseguir y capacidad de hacerlo.

La ausencia de tipos nacionales suficientes y consecuentes con los internacionales, así como otras diferencias o discrepancias normativas, a tal punto profundas que conduzcan a la dilusión del sistema de responsabilidad penal y lucha contra la impunidad que se convino en Roma, acredita-

89 Una evidente aplicación del principio de oportunidad se advierte en el caso de los delitos contra la administración de justicia. En esta hipótesis, la corte consulta a los Estados partes en el estatuto que pudieran tener jurisdicción respecto del delito, y considera diversos factores que hacen aconsejable o no que ejerza su jurisdicción en la especie (regla 162). Inclusive, hay factores de oportunidad relacionados específicamente con el Estado anfitrión: " $L$ a corte dará consideración favorable a la solicitud del Estado antitrión de que renuncic a su facultad para ejercer la jurisdicción en los casos en que el Estado anfitrión considere que la renuncia revista especial importancia” (idem, pfo. 3). Finalmente, si la corte resuejve no ejercer su jurisdicción, podrá solicitar a un Estado parte que lo haga (idem. pfo. 4). 
rían, casi seguramente, falta de voluntad persecutoria. Para evitarlo, los Estados necesitan revisar su legislación a la luz de las normas del estatuto - y de los elementos de los crímenes-, con el fin de asegurar que a la voluntad de perseguir, que se supone existe en un Estado parte, corresponda la herramienta para conseguirlo. ${ }^{90}$

Este objetivo se puede lograr mediante aplicación inmediata de las disposiciones materiales internacionales por parte de los jueces internos, ${ }^{91}$ o a través de la recepción de aquéllas en el derecho doméstico, cosa que se ha urgido en diversas ocasiones, acaso sobre todo en lo que respecta a las violaciones contra el derecho internacional humanitario. ${ }^{92}$ Estas soluciones no implican que se abandone el examen del principio de legalidad en el Estatuto de Roma, al que me referiré infra. El sistema de aplicación inmediata de normas sustantivas no supone abundantes cambios en la legislación material nacional, aunque los haya en el régimen de colaboración. El de aplicación mediata puede desencadenar procesos de reforma más o menos abundante: habría que revisar los tipos y las penas, y reconstruir la tipificación y la punición conforme a los estándares internacionales. Esto puede significar para el Estado parte una verdadera obligación, si la impone el instrumento internacional,,${ }^{93}$ o bien, sólo una carga —n el

90 Sin embargo, una vez establecida la idoneidad penal nacional, en virtud de su congruencia con la internacional (tipos y punibilidades), queda en pie la pregunta que se formula en este trabajo acerca del efecto que pudiera acarrear la excesiva benevolencia ejecutiva de un sistema nacional que excluyera de jure y de facto la efectiva punición del delito a través de sustitutivos o beneficios que hagan ilusoria la persecución.

91 Así, por ejemplo, en el sistema mexicano conforme a la estipulación del artículo 133 de la Constitución general de la república, que permite —-mejor aủn, ordena- a los tribunales de la república aplicar los tratados internacionales - lo serían, en la especie, los Convenios de Ginebra y el Estatuto de Roma, con sus respectivos tipos penales - a los casos que conozcan, tomando en cuenta que esos ordenamientos forman parte de la ley suprema de la Unión: son, pues, normas de fuente no nacional constitucionalmente incorporadas en el derecho nacional y que por ello forman parte de éste.

92 Cfr. Dutli, María Teresa, "La represión, a nivel nacional, de las violaciones de las normas del derecho internacional humanitario y los trabajos del Servicio de Asesoramiento del CICR" y "Recomendaciones de la Sociedad Internacional de Derecho Militar y de Derecho de la Guerra sobre los principios esenciales de la represión nacional de las infracciones graves del derecho de los conflictos armados", en varios, Represión nacional de las violaciones del derecho internacional humanitario (sistemas romano-germánicos). Reunión de expertos, Ginebra, Comité Internacional de la Cruz Roja, 1998, pp. 24 y 25 , y pp. 141 y ss, respectivamente. Asimismo, cfr. Benavides, Luis, "La obligación de los Estados de reprimir los crimenes de guerra como parte de una justicia penal internacional", Revista Mexicana de Derecho Público, núm. 3, abril de 2002, pp. 35 y ss.

93 Verbi gratia, tipificación penal de diversas conductas constitutivas de esclavitud o trata de esclavos (articulos 20. y 6o. de la Convención relativa a la Esclavitud, de 1926, y 30., 50. y 60. de la Convención Suplementaria sobre la Abolición de la Esclavitud, la Trata de Esclavos y Prácticas Análogas a la Esclavitud, de 1956), penalización de diversas conductas de discriminación y odio racial (articulo 40 . de la Convención Internacional sobre la Eliminación de todas las Formas de Discrimina- 
sentido procesal de la palabra- ${ }^{94}$ para evitar que se aplique, por defecto de la ley nacional y de la correspondiente jurisdicción, la ley internacional en manos de la jurisdicción respectiva.

La sabiduría individual de los magistrados y la colectiva del tribunal permitián sortear con fortuna los escollos que todo esto propone, y de cuya feliz solución depende la credibilidad de la Corte Penal Internacional y su buena imagen ante las jurisdicciones nacionales, de cuya propia buena imagen, a su vez, dará cuenta la corte en sus pronunciamientos sobre admisibilidad. Pero no se trata sólo, por supuesto, de "buenas imágenes", sino de relación positiva —en aras del sistema mundial — entre los eslabones de la cadena: el nacional y el internacional.

\section{VIII. "RECUPERACIÓN DE LA COMPETENCIA"}

La operación de la complementariedad sugiere otros temas, entre ellos el que se pudiera llamar "recuperación del ejercicio de la competencia por la justicia nacional", 95 una vez que se ha despachado y concluido - por alguna forma de terminación prevista en el estatuto- el ejercicio de la jurisdicción internacional. En esta recuperación surge el reencuentro, por sí decirlo, entre la jurisdicción internacional, que había avanzado, y la nacional, que se había retraído. El hecho de que aquélla hubiese iniciado el conocimiento del asunto no impide que éste derive a un tribunal interno. ${ }^{96}$

ción Racial, de 1966), medidas para sancionar a los responsables de genocidio (artículos 1o. y 4o. de la Convención sobre la Prevención y el Castigo del Crimen de Genocidio, de 1948), medidas para perseguir, enjuiciar y castigar a los responsables del crimen de apartheid (artículo IV de la Convención Intemacional sobre la Represión y Castigo del Crimen de Apartheid, de 1973).

94 Escribe Eberhard Schmidt, siguiendo el pensamiento de Goldschmidt: "Si una de las partes quiere impedir que se produzcan situaciones procesales que no desea, le incumbe la 'carga' de ejecutar los actos tendientes a impedirlas. La fuerza motivadora que resuita de esto no se puede confundir con el 'deber' que deriva de una norma juridico material. Este punto de vista muestra la diferencia fundamental del pensamiento jurídico material y del pensamiento procesal". Schmidt, Eberhard, Los fundamentos teóricos y constitucionales del derecho procesal penal, trad. de José Manuel Núñez, Buenos Aires, Bibliográfica Omeba, 1957, p. 51.

95 O bien, "recuperación de la competencia", si se entiende que ésta se tuvo originalmente pero fue relevada $-\mathrm{y}$ en consecuencia se perdió- al intervenir la $\mathrm{CPl}$, que de esta manera devino tribunal competente para conocer sobre la cuestión litigiosa.

96 En el sistema estatutario de cosa juzgada, "nadie será procesado por otro tribunal en razón de uno de los crimenes mencionados en el articulo 5o. por el cual la corte ya lo hubiere condenado o absuelto" (artículo 20.2). Al contrario, sería posible el juicio nacional cuando la corte ha cerrado el proceso sin emitir sentencia. 


\section{Atipicidad internacional y tipicidad nacional}

La hipótesis más evidente de recuperación de la competencia se encuentra en aquellos casos sometidos al conocimiento de la CPI que no culminan en sentencia condenatoria -no obstante existir cierta conducta violatoria de bienes de suma relevancia-en virtud de que éstos se hallan total o parcialmente fuera del marco típico establecido por el estatuto. La aticipidad internacional -y la consiguiente impunidad del mismo carácter- de hechos inicialmente señalados como constitutivos de genocidio pudiera obedecer a que el agente no realizó aquéllos "con la intención de destruir total o parcialmente a un grupo nacional, étnico, racial o religioso como tal", o a que los hechos cobraron víctimas individuales, fuera de cualquier connotación de grupo (artículo 6o.); y la exclusión de crímenes de lesa humanidad pudiera deberse a que los actos ilícitos no son "parte de un ataque generalizado o sistemático contra una población civil y con conocimiento de dicho ataque" (artículo 5.1); y la de crímenes de guerra pudiera derivar de que las conductas no son "parte de un plan o política" o "de la comisión en gran escala de tales crímenes" (artículo 8.1).

Obviamente, muchos hechos descartados por la jurisdicción internacional debido a que son atípicos bajo las reglas del estatuto, deben ser absorbidos por la nacional, conforme a sus propias tipificaciones, que pueden abarcar con claridad casos de homicidio, lesiones, tortura, desaparición forzada, violación sexual y otras conductas extraordinariamente graves, que se hallan sancionadas por la ley interna con penas elevadas, no menos severas que las dispuestas por el estatuto. ${ }^{97}$

\section{Oportunidad y pertinencia conforme a la norma internacional}

Una de las hipótesis más importantes para esta recuperación es la que se presenta con motivo de la aplicación de consideraciones de oportunidad por parte del tribunal internacional, que ampliamente autoriza el Estatuto de Roma: oportunidad que lleva a declinar el conocimiento de unos hechos que conservan integramente - sin embargo- su condición delictuosa y no debieran quedar impunes. Si esto ocurriera, tras el episódico conocimiento por parte del tribunal internacional, la justicia de este carácter habría contribuido a la impunidad, en vez de reducirla, como es uno de sus objetivos declarados. 
La oportunidad entra en juego a propósito de dos nociones cuyo alcance habrá de establecer la corte en su futura jurisprudencia. Me refiero a la gravedad de los hechos delictuosos y al interés de la justicia, que no son necesariamente expresiones sinónimas. La primera tiene que ver con el bien jurídico afectado y la magnitud de la lesión causada, y el segundo con la pertinencia de perseguir y sancionar, tomando en cuenta las características del caso y la forma en la que éste se proyecta sobre su circunstancia, que es también el contexto en el que se desenvuelve la jurisdicción de la corte y que no podría ni debería perder de vista el tribunal. La invocación de la justicia abarca también, como se desprende con claridad de algunos preceptos que adelante mencionaré, una referencia a la equidad, la seguridad, la paz, la conveniencia social o política, el mal menor.

El estatuto compromete la naciente jurisdicción sólo con los "crímenes más graves de trascendencia para la comunidad internacional en su conjunto", como se dice en el preámbulo y en el artículo $10 .{ }^{98}$ Se trata, en estas expresiones, de señalar el fundamento del estatuto y acotar el alcance de éste. Por lo tanto, podría considerarse que la gravedad de los crímenes sujetos a la competencia de la corte ya ha sido determinada —digamos: predeterminada - por el estatuto, y que la corte no puede ni debe hacer otra cosa que entender que todos los hechos recogidos en los artículos 6o. a 8o. son los crímenes más graves de trascendencia internacional, sin aventurarse en apreciaciones de política criminal propias de un legislador, no de un juzgador.

Empero, me permito suponer que alguna vez se planteará a la CPI la idea de que alguno de los hechos que encuadran en las descripciones típicas de aquellos preceptos no deben ser considerados, sin embargo, bajo la condición de crímenes más graves de trascendencia internacional. Si esto sucede, la corte se verá en la necesidad de analizar el concepto general en los términos del asunto particular, sea para rechazar in limine y de plano el argumento, por referirse a un punto ajeno a sus atribuciones estricta-

98 En el preámbulo, los Estados afirman "que los crímenes más graves de trascendencia para la comunidad internacional en su conjunto no deben quedar sin castigo y que, a tal fin, hay que adoptar medidas en el plano nacional e intensificar la cooperación internacional para asegurar que sean efectivamente sometidos a la acción de la justicia", y manifiestan en consecuencia su decisión de establecer una Corte Penal Internacional "que tenga competencia sobre los crímenes más graves de trascendencia para la comunidad internacional en su conjunto". En su momento, el artículo lo. señala que "ja competencia de la corte se limitará a los crímenes más graves de trascendencia para la comunidad internacional en su conjunto", y a continuación enuncia varias categorías -genocidio, lesa humanidad, guerra y agresión- en las que se concentran, por ahora, esos crimenes especialmente graves cuyo conocimiento se ha querido atribuir a la corte. 
mente jurisdiccionales, sea para abordar el hecho específico y confrontarlo con la ratio juris de la disposición genérica.

Además de las referencias acerca de la gravedad de la infracción que contiene el artículo 80., a propósito de los crímenes de guerra, hay alusiones a gravedad del delito e interés de la justicia en otros pasajes del ordenamiento internacional. En el rubro de la admisibilidad, el tribunal se enfrenta a la "gravedad suficiente" $" 99$ del asunto para justificar la adopción de medidas adicionales a las que hubiese adoptado o previsto el Estado conforme a su legislación interna, y por lo tanto, para asumir el conocimiento o permitir que éste siga en el cauce de la jurisdicción doméstica. También se toma en cuenta la gravedad del delito - en este caso, por parte del tribunal interno que colabora con la justicia internacional-, cuando se trata de resolver sobre la libertad provisional del inculpado (artículo 59.4), y por parte del tribunal internacional cuando resuelve sobre la prisión o libertad durante la apelación. ${ }^{100}$ Desde luego, la gravedad del crimen figura entre los elementos conducentes a la individualización de la pena (artículos 77.1.b y 78.1).

El fiscal debe adoptar las determinaciones que considere pertinentes a propósito de: a) La procedencia de la investigación, y $b$ ) La procedencia del enjuiciamiento una vez realizada la investigación. En cada uno de estos casos se suscita el tema que ahora nos ocupa. Cuando el fiscal analiza y resuelve sobre la pertinencia de iniciar una investigación, ${ }^{101}$ debe considerar, entre otros factores, si "existen razones sustanciales para creer que,

99 El artículo 17, un precepto crucial en lo que respecta a la complementariedad -que se invoca mediante remisión directa al décimo párrafo del preámbulo y al artículo 10.-, dice que la corte "resolverá la inadmisibilidad de un asunto cuando.... d) El asunto no sea de gravedad suficiente para justificar la adopción de otras medidas por la corte". Obviamente, aquí no se alude a la tipicidad del hecho -que se supone prevista en el estatuto--, sino a su gravedad, que es el dato a considerar para que la CPI resuelva intervenir o abstenerse.

100 Se trata de la hipótesis de impugnación de la sentencia absolutoria. "En circunstancias ex+ cepcionales y teniendo en cuenta entre otras cosas... la gravedad del delito..., la Sala de Primera Instancia, a solicitud del fiscal, podrá decretar que (el acusado) siga privado de la libertad mientras dure la apelación" (artículo 31.3.c.i).

101 La investigación se inicia de oficio "sobre la base de información acerca de un crimen de la competencia de la corte". Primero debe acreditarse la veracidad de la información recibida. Si hay fundamento para abrir la investigación (para determinarlo, el fiscal tomará en cuenta la estipulación del artículo 53 -que examino en la nota infra-, conforme a la regla 48), el fiscal solicitara la autorización de la Sala de Cuestiones Preliminares, cuya negativa no impide que el fiscal "presente ulteriormente otra petición basada en nuevos hechos o prucbas relacionados con la misma situación" (artículos 15, en relación con el 13.c). Desde luego, hay otros actos que impulsan la actividad indagatoria dè fiscal: remisión por un Estado parte (articulo 13.a) y remisión por el Consejo de Seguridad (artículo 13.b). 
aun teniendo en cuenta la gravedad del crimen y los intereses de las víctimas (que serían motivos suficientes para actuar, en estricta justicia), una investigación no redundaría en interés de la justicia" (artículo 53.1.c). Hecha la investigación - y bajo este mismo ejercicio de apreciación que se encomienda a la Fiscalía-, el fiscal puede llegar a la convicción de que "el enjuiciamiento no redundaría en interés de la justicia, teniendo en cuenta todas las circunstancias, entre ellas la gravedad del crimen, los intereses de las víctimas y la edad o enfermedad del presunto autor y su participación en el presunto crimen" (artículo 53.2.c).

Por todo ello - y por mucho más - la figura del fiscal y el desempeño de sus atribuciones adquieren un valor eminente en el conjunto de la jurisdicción penal internacional. No en balde ha llegado a ser el fiscal la figura más alentadora para las organizaciones no gubernamentales, que pueden instar la persecución de crímenes a través de la iniciativa del fiscal, cosa que difícilmente conseguirían por medio de las facultades impulsoras depositadas en los Estados o en el Consejo de Seguridad. Y por esto mismo, algunos Estados poderosos vieron con preocupación el fortalecimiento del fiscal, a un punto tal que declararon abiertamente su preocupación de que este funcionario se convirtiese en un "Doctor Strangelove prosecutor", en alusión al filme estadounidense que muestra a un científico desequilibrado que se empeña en desencadenar una guerra nuclear. La prudencia y "selectividad" del fiscal serán factores relevantes en el éxito de la jurisdicción internacional. ${ }^{102}$

En este punto se despliegan, una frente a otra, las atribuciones indagatorias y estimatorias del fiscal y las facultades controladoras y valorativas de la corte, a través de la Sala de Cuestiones Preliminares. ${ }^{103}$ Es notorio que tanto aquél como ésta traen a cuentas referencias jurídicas y políticas; no sería posible excluir ninguna de estas categorías si se trata de resolver sobre "el interés de la justicia", apreciando para ello los elementos acogidos en el artículo 53.1. Aun cuando la regulación del procedimiento a seguir dista mucho de ser particularmente clara, ${ }^{104}$ me parece

102 Cfr. Schabas, op. cit., nota 17, pp. 97 y ss.

103 Bajo esta denominación se agrupan diversas figuras procesales relacionadas con la procedencia o la pertinencia de la investigación y el proceso (admisibilidad y competencia), cooperación procesal, medidas precautorias (en relación con personas: detención y libertad, y cosas: medios de prueba o bienes), apreciación de cargos y confirmación de cargos.

104 Fundo esta opinión en las siguientes consideraciones: 1. El artículo 53 se refiere a dos etapas del procedimiento, cada una con sus respectivas actuaciones: a) por una parte, la que se inicia con cierta información en poder del fiscal y culmina con la decisión de éste sobre la pertinencia de iniciar - 
razonable entender que la conclusión del fiscal, tanto acerca del inicio de la investigación, como en torno a la pertinencia del enjuiciamiento, deben ser sometidas a la Sala de Cuestiones Preliminares.

La Sala de Cuestiones Preliminares puede examinar la decisión del fiscal y pedir a éste, si así lo solicitan el Estado que envió el asunto o el Consejo de Seguridad, cuando la instancia provino de éste, que reconsidere la decisión (artículo 53.3.a). ${ }^{105}$ Aquella sala podrá revisar de oficio la decisión del fiscal si se basa sólo en la causal relativa al interés de la justicia. "En ese caso, la decisión del fiscal únicamente surtirá efecto si es confirmada por la Sala de Cuestiones Preliminares" (artículo 53.3), en la inteligencia de que cuando la sala no confirme la decisión del fiscal, "éste deberá iniciar una investigación o proceder al enjuiciamiento" (regla 110). ${ }^{106}$

una investigación, analizando para ello diversos elementos (1 a, b y c), entre ellos el interés de la justicia (1.c), y b) por otra parte, la que comienza cuando el fiscal ha concluido ya la investigación ("tras la investigación") y culmina con una conclusión motivada que se presenta a la Sala de Cuestiones Preliminares. La sección I del capitulo 5 de las Reglas de Procedimiento y Prueba se denomina "Decisión del fiscal respecto del inicio de una investigación de conformidad con los párrafos 1 y 2 del artículo 53". Esta denominación errónea no impide que en seguida se haga un deslinde acertado: "decisión del físcal de no iniciar una investigación" (regla 105) y "decisión del fiscal de no proceder al enjuiciamiento" (regla 106). 2. Dentro de la primera etapa, si el fiscal considera que no hay fundamento razonable para la investigación y esa determinación se basa solamente en el interés de la justicia (1.c), lo comunicará a la Sala de Cuestiones Preliminares (1, in fine; sobre esto, cfr. regla 105); no se dispone lo mismo en cuanto a la determinación basada en los otros datos del párrafo 1 del artículo 53, distintos del interés de la justicia, lo cual permitiría concluir que la determinación sustentada en esos otros datos no se halla sujeta al control de la sala. 3. Dentro de la segunda etapa, el fiscal debe notificar su conclusión motivada a la sala y, además, al Estado o al Consejo de Seguridad, en sus respectivos casos (se supone, pues, que éstos trasladaron al fiscal el conocimiento de la situación). Sólo en este momento se alude al Estado y al consejo. 4. Tanto aquél como éste pueden requerír a la sala que examine la decisión del fiscal (no se distingue acerca del fundamento de ésta) "de no proceder a la investigación de conformidad con el párrafo I (que se refiere a la primera etapa: antes de la investigación) o el párrafo 2 (que se refiere a la segunda etapa: después de la investigación: "tras la investigación") (énfasis agregado) (3.a). Evidentemente aquí hay una incongruencia. 5. En la misma segunda etapa, la sala puede revisar de oficio "una decisión del fiscal de no proceder a la investigación si dicha decisión se basare únicamente en el párrafo l c) (nuevamente, la etapa anterior a la investigación) o el párrafo 2 c)" (la etapa posterior a la investigación) (énfasis agregado) (3.b). Tambićn aquí es manifiesta la incongruencia. 6. En relación precisamente con esta última frase del párrafo 3, inciso b, en este mismo aparece la siguiente expresión: "En ese caso (el de los párrafos l.c y 2.c) la decisión del fiscal únicamente surtirá efecto si es confirmada por la Sala de Cuestiones Preliminares". Añadamos aquí la disposición de la regla 110: si la sala no confirma la decisión del fiscal, "éste deberá iniciar una investigación o proceder al enjuiciamiento".

105 La regla 108 previene que el fiscal debe hacer "lo antes posible" la reconsideración pedida por la Sala de Cuestiones Preliminares (1). La "decisión definitiva" del fiscal será comunicada a la sala y a quienes hayan participado en la reconsideración (2).

106 En rigor, quien procede al enjuiciamiento es la corte; el fiscal lo promueve mediante el ejercicio de la acción. 
Hay más invocaciones del interés de la justicia, en un sentido diferente, que puede equivaler a buen desarrollo del proceso, acceso del reo a la justicia, obtención de la verdad, emisión de una sentencia justa. Esto sucede cuando se indica que la persona sujeta a investigación tiene derecho a contar con defensor de oficio, "siempre que fuere necesario en interés de la justicia"; ${ }^{107}$ otro tanto se dice en relación con la etapa de proceso. ${ }^{108}$ Ante semejante señalamiento es pertinente la declaración formulada por Colombia, a la que antes me referí: siempre será en interés de la justicia que el inculpado cuente con la asistencia de un abogado. ${ }^{109}$ En la misma línea se dota al inculpado prófugo o ausente de defensor cuando venga al caso la confirmación de cargos ante la Sala de Cuestiones Preliminares y ésta "resuelva que ello redunda en interés de la justicia" (artículo 61.2.b).

Todavía se plantean otras hipótesis de interés de la justicia, en relación con la verdad histórica y la actividad probatoria. Por este motivo _."interés de la justicia y en particular... interés de las víctimas"-, la Sala de Primera Instancia puede pedir al fiscal que presente más pruebas - "pruebas adicionales" — o disponer que continúe el proceso a pesar de que exista confesión - "declaración de culpabilidad"- del procesado (artículo 65.4). Por la misma razón, la sala puede desechar los acuerdos entre el fiscal y la defensa para considerar probado un hecho (regla 69). Finalmente, "en interés de la justicia" la corte podrá sesionar en un Estado distinto del anfitrión (regla 100.1).

En algunas de las situaciones a las que me he referido, la investigación del fiscal no prospera o el proceso ante la CPI concluye sin sentencia que resuelva sobre la existencia de hechos delictuosos y la responsabilidad penal —o ausencia de ella— del inculpado. Pero no hay decisión de

107 Entre los derechos de la persona en esa etapa del procedimiento, figura el de "ser asistida por un abogado defensor de su elección o, si no lo tuviere, a que se le asigne un defensor de oficio, siempre que fuere necesario en interés de la justicia y, en cualquier caso, sin cargo si careciere de medios suficientes" (artículo 55.2.c). Queda fuera del presente trabajo el estudio de los derechos del inculpado. Cfr., al respecto, González Casanova, Joaquin, "Los derechos de los inculpados frente a la Corte Penal Internacional", en Guevara y Valdés, La Corte Penal Internacional..., cit., nota 60, pp. 113 y ss.

108 Es derecho del acusado "ser informado, si no tuviera defensor, del derecho que le asiste a tenerlo y, siempre que el interés de la justicia lo exija, a que se le nombre defensor de oficio, gratuitamente si careciere de medios suficientes para pagarlo" (artículo 67.l.d).

109 La expresión "siempre que fuere necesario en interés de la justicia" resulta "odiosa" en estos casos. "Obviamente es siempre en interés de la justicia que todo acusado, inocente mientras el fallo no resulte condenatorio y final, cuente con todos los medios de defensa a su alcance. Y ello no puede interpretarse como un exceso garantista, sino como la ejecución del más alto servicio que se pueda rendir a la causa de la justicia". Rodríguez Carrión, op cit., nota 18, p. 499. 
fondo: la contienda penal se mantiene insoluta. Por otra parte, no existe norma que proyecte sobre esos casos la regla ne bis in idem por parte de la jurisdicción doméstica. Recuérdese, para los efectos que interesan ahora, que el estatuto dispone en materia de cosa juzgada que "nadie será procesado por otro tribunal (además de la CPI) en razón de uno de los crímenes mencionados en el artículo 5o. por el cual la corte ya le hubiere condenado o absuelto" (artículo 20.2), disposición que no abarca, obviamente, el supuesto en que el fiscal investigue y la corte procese a un sujeto sin que estos procedimientos culminen en sentencia absolutoria o condenatoria.

Es entonces que aparece lo que he denominado "recuperación del ejercicio de la competencia por la jurisdicción nacional". No operó —por motivos de oportunidad - la función complementaria de la justicia internacional, pero esto no puede traducirse en la impunidad del sujeto. Este sería sancionable más allá de las consideraciones de gravedad del crimen o interés de la justicia que esgrime la Corte Penal Internacional. No se debe atar a los tribunales nacionales e impedirles recuperar su competencia sobre el caso y aplicar la ley en la forma en que sea debido hacerlo. Dicho de otra manera, la terminación del procedimiento internacional mediante un acto que por su propia naturaleza no supone absolución o condena, no confiere al inculpado inmunidad ante la justicia interna. La gravedad o el interés de la justicia que en su hora ponderó la CPI sólo para los efectos de su propia competencia, podrán merecer también - si la ley lo autoriza- el análisis de la jurisdicción nacional. El "juego" entre legalidad y oportunidad, resuelto de un modo en el plano internacional, pudiera serlo de la misma o de otra manera en el plano nacional.

\section{Suspensión del procedimiento}

Lo que llevo dicho no resuelve el problema que se suscita en la hipótesis de mayor relevancia del principio de oportunidad, a saber: cuando el Consejo de Seguridad dispone que se suspenda durante cierto tiempo -que puede ser mucho, o incluso todo el tiempo- la investigación o el enjuiciamiento ya iniciados. ${ }^{110} \mathrm{La}$ intervención del consejo se sustenta en con-

110 El fundamental artículo 16 , que ha sido objeto de nutridos comentarios y frecuentes controversias, señala: "En caso de que el Consejo de Seguridad, de conformidad con una resolución aprobada con arreglo a lo dispuesto en el capitulo VII de la Carta de las Naciones Unidas, pida a la corte que suspenda por un plazo que no podrá exceder de doce meses la investigación o el enjuiciamiento que haya iniciado, la corte procederá a esa suspensión; la petición podrá ser renovada por el Consejo 
sideraciones que van más allá de la tipicidad penal —a la luz del estatuto- de la conducta atribuida al inculpado: analiza, en efecto, la existencia de una "amenaza a la paz, quebrantamiento de la paz o acto de agresión" (artículo 39 de la Carta de las Naciones Unidas. Este es un pedimento que no pueden resistir el fiscal o la corte. Los críticos de la facultad conferida al consejo señalan que la suspensión de investigaciones o procesos en función de la paz pone a ésta en pugna con las exigencias de la justicia. Asi lo señaló la India en la Conferencia de Roma. ${ }^{111}$ Un dilema, por cierto, que no quisiéramos plantearnos.

La suspensión provoca una crisis en la operación del principio de complementariedad. La razón de ser de éste _además de ciertos puntos de principio- es el combate contra la impunidad: interviene la justicia internacional, en forma complementaria con respecto a la nacional, porque ésta no quiso o no pudo actuar adecuadamente. Pero la intervención suspensiva del Consejo de Seguridad invierte las cosas: es la justicia internacional la que no quiere actuar, independientemente de que lo pretendan —en algún momento- las jurisdicciones originalmente llamadas a conocer del caso: la territorial, la que corresponda según la regla de nacionalidad activa o pasiva e incluso la que lo proponga conforme al principio de jurisdicción universal en su vertiente estatal.

El estatuto no previene qué hacer en tales circunstancias, más allá de la mera suspensión del procedimiento internacional. El silencio del ordenamiento de Roma no nos autoriza a suponer - io sí? - que las jurisdicciones domésticas pueden recuperar su atribución natural. El caso ha quedado entre las "mallas" de la justicia internacional, y dificilmente podría ser extraído de ahí a pesar de la corte, cuya actividad sólo se paralizó, pero cuya competencia no cesó, e incluso del Consejo de Seguridad, que ha estimado improcedente la persecución del delito en virtud de ciertos motivos -principio de oportunidad- vinculados con la paz y la seguridad internacionales. ¿Cómo podría hacer la jurisdicción nacional, enfren-

de Seguridad en las mismas condiciones". Esta renovabilidad a través de acuerdos sucesivos podria dejar un asunto fuera del conocimiento de la corte en forma prácticamente indefinida.

111 La delegación de este país señaló: "I_a facultad para bloquear es en algunos sentidos igualmente dura de entender o de aceptar. Por una parte, se argumenta que estamos creando la CPI para tratar los crimenes de magnitud más grave. Pero por la otra, se argumenta que el mantenimiento de la paz internacional y la seguridad pueden requerir de que aquellos que han cometido estos crímenes puedan escapar a la justicia, si el consejo asi lo prescribe. Hasta el momento este argumento se ha acatado, la conferencia acepta la proposición de que la justicia podría socavar la paz internacional y la seguridad". Bergsmo, op. cit., nota 45, p. 202. 
tando al Consejo de Seguridad de las Naciones Unidas, lo que no pudo hacer la propia Corte Penal Internacional, que, por lo demás, como he dicho, mantiene íntegra su competencia para juzgar —algún día: cuando el obstáculo se remueva - sobre los hechos temporalmente sustraídos a la investigación o al proceso?

\section{Responsabilidad colectiva}

La justicia interna puede asumir el conocimiento de hechos planteados ante la internacional en otro caso. Aludo al supuesto de la responsabilidad colectiva. Como se sabe, el Estatuto de Roma no ha regulado la responsabilidad colectiva: la justicia internacional sólo se ejerce sobre "personas naturales", 112 a diferencia de lo que se previno para el Tribunal de Nüremberg, ${ }^{113}$ creando así un fundamento para la imposición de sanciones individuales. ${ }^{114} \mathrm{El}$ estatuto sólo alude a la responsabilidad de individuos participantes - bajo determinados títulos o en ciertas situaciones- en los delitos sujetos a represión. No se restringe el universo en función de la relevancia de los crímenes o de la participación delictuosa, como se hizo en Nüremberg ${ }^{115}$ y se postula en Sierra Leona. ${ }^{116}$

112 El articulo 25 del estatuto, referente a "Responsabilidad penal individual", señala: "1. De conformidad con el presente estatuto, la corte tendrá competencia respecto de las personas naturales-2. Quien cometa un crimen de la competencia de la corte será responsable individualmente y podrá ser penado de conformidad con el presente estatuto".

113 Conforme a la Carta de 1945, el Tribunal Militar Internacional podía declarar que el grupo o la organización a la que pertenecía un inculpado era una "organización criminal" (articulo 90.). Una vez formulada esta declaratoria, la autoridad judicial nacional de las potencias suscriptoras de aquélla podrían enjuiciar a los miembros de tal organización, en la inteligencia de que habia quedado probado y no podría ser impugnado el carácter delictuoso de ésta (artículo 10).

114 No hubo condenas en masa. El crimen de organización fue sancionado con medidas politicas bajo las leyes de "desnazificación". Cfr. Zayas, Alfred-Maurice de, "El proceso de Nüremberg ante el Tribunal Militar Internacional", en Demandt, Alexander (ed.), Los grandes procesos. Derecho y poder en la historia, trad. de Enrique Gavilán, Barcelona, Crítica, 1993, p. 248.

115 El acuerdo entre las potencias vencedoras, del 8 de agosto de 1945, lievaba precisamente la denominación de "Agreement for the Prosecution and Punishment of the Major War Criminals of the European Axis", y en el artículo 1o. de la Carta derivada del acuerdo se previno que el tribunal atenderia al "just and promp trial and punishment of the major war criminals of the European Axis" (énfasis agregado).

116 En el artículo 1.1 del Acuerdo entre las Naciones Unidas y el Gobierno de Siena Leona acerca del Establecimiento de un Tribunal Especial para Sierra Leona (2002) se fundamenta la competencia del órgano jurisdiccional para procesar a las personas "a quienes quepa la mayor responsabilidad por las infracciones graves..." (énfasis agregado). En el informe del secretario general al Consejo de Seguridad se indica que "la expresión 'más responsables' se refiere a una posición de liderazgo o de autoridad de los acusados y a cierto grado de gravedad del delito o a su comisión en masa. Sin embargo, ha de considerarse no un baremo ni un limite mínimo para que se ejerza una competencia especifica, sino una orientación para el fiscal, con objeto de que éste adopte una estrategia 
Aquella restricción subjetiva, que sólo considera personas, no excluye la responsabilidad internacional del Estado, sujeta a sus propias reglas, ${ }^{117}$ que no pretendo examinar ahora. ${ }^{118}$ La limitación, que se ha cuestionado, ${ }^{119}$ desemboca en el olvido internacional de una responsabilidad penal que pudiera existir, en cambio, conforme a la legislación nacional. Así las cosas, nada impediría —en mi concepto- que la cuestión retornara ante la jurisdicción interna para que ésta dedujera las consecuencias que ella suscita en orden a la responsabilidad de personas colectivas. Se podría considerar acreditada la responsabilidad del individuo, y a partir de ahí analizar, con los datos pertinentes —que fueron irrelevantes para la CPI, pero serían relevantes para el tribunal doméstico-, la relación que exista entre la conducta individual y la persona colectiva, todo ello de conformidad con las estipulaciones que la ley nacional contenga sobre esta compleja materia. En la especie no habría bis in idem, en tanto el justiciable sería otra persona.

\section{Reparación del daño}

Una hipótesis más de "recuperación de competencia por la justicia nacional" puede plantearse a propósito de la reparación del daño. La jurisdicción penal internacional se halla sustentada en varios conceptos que constituyen otros tantos objetivos que esa función procura: recuperar el imperio del derecho, alterado por el crimen cometido; aplicar, por ello y

de acusación y decisiones de procesamiento en determinados casos". Consejo de Seguridad, Informe del Secretario General sobre el Establecimiento de un Tribunal Especial para Sierra Leona, S/2000/915, 4 de octubre de 2000 , p. 7.

117 "Nada de lo dispuesto en el presente estatuto respecto de la responsabilidad penal de las personas naturaies afectará a la responsabilidad penal del Estado conforme al derecho internacional" (artículo 25.4).

118 En el Proyecto de Artículos sobre la Responsabilidad de los Estados, de la Comisión de Derecho Internacional de Naciones Unidas, a la que me referí (supra nota 42), se propone establecer la responsabilidad de aquéllos por hechos ilicitos, incluso crímenes y delitos internacionales. "E1 hecho intemacionalmente ilícito resultante de una violación por un Estado de una obligación internacional tan esencial para la salvaguarda de intereses fundamentales de la comunidad internacional que su violación está reconocida como crimen por esa comunidad en su conjunto constituye un crimen internacional... Todo hecho internacionalmente ilicito que no sea un crimen internacional... constituye un delito internacional" (artículo 19.2 y 4).

$119 C f r$, entre otros autores, a Baigún, quien propone un sistema de doble imputación para establecer la responsabilidad del individuo, pero también "la responsabilidad de la persona jurídica por la realización del injusto institucional"; esta "responsabilidad social es una categoría compleja y sus componentes o elementos: la atribuibilidad y (la) exigibilidad, registran tanto situaciones de hecho como ingredientes de valoración". Baigún, David, op. cit., nota 74, p. 99. 
para ello, la pena correspondiente al individuo responsable; devolver el orden y la paz a la sociedad afectada, y reparar el daño causado a quien es, verdaderamente, el otro sujeto en la relación sustantiva que se analiza y resuelve bajo la justicia penal: el sujeto pasivo, la víctima del delito, a la que en algunos sistemas nacionales se denomina el ofendido. Este, titular inmediato de los bienes jurídicos violentados o puestos en peligro - vida, libertad, integridad, por ejemplo- ${ }^{120}$ tiene, en tal virtud, un derecho material al resarcimiento como consecuencia del agravio que ha sufrido. Evidentemente, la víctima puede ser una persona individual, una persona colectiva, una población, etcétera.

El artículo 75 del estatuto gobierna la reparación a las víctimas. Para ello concede a la corte una expresa facultad normativa sobre las características que tendrá, en general, la reparación del daño. En la decisión de los casos particulares, la corte se "podrá" ajustar a las normas que fije dentro de esa potestad. ${ }^{121}$ Es preciso resolver la forma en que se emitirá aquella regulación. Dados los términos que a este respecto utiliza el estatuto se puede entender que la CPI emitirá un ordenamiento específico -como puede expedir su propio reglamento—, o bien, establecerá esas normas a través de su jurisprudencia.

Ahora bien, conforme al mismo artículo 75, el pronunciamiento de la corte sobre este extremo de la responsabilidad del infractor se dicta, regularmente, en virtud de la promoción y pretensión del interesado, y sólo excepcionalmente de oficio. Esto significa que será el interesado -l derechohabiente, digamos - quien generalmente desencadene la determinación de la corte en torno a esta cuestión de fondo, ${ }^{122}$ habida cuenta del

120 Las Reglas de Procedimiento y Prueba se ocupan en el régimen de las victimas (sección III). La regla 85 entiende por víctimas "a las personas naturales que hayan sufrido un daño comro consecuencia de la comisión de algún crimen de la competencia de la corte"; también se podrá entender que son víctimas "las organizaciones o instituciones que hayan sufrido daños directos a alguno de sus bienes que esté dedicado a la religión, la instrucción, las artes, las ciencias o la beneficencia o a sus monumentos históricos, hospitales y otros lugares y objetos que tengan fines humanitarios".

121 EJ artículo 75.1 señala: "La corte establecerà principios aplicables a la reparación, incluidas la restitución, la indemnización y la rehabilitación, que ha de otorgarse a las víctimas o a sus causahabientes. Sobre esta base, la corte, previa solicitud u oficio en circunstancias excepcionales, podrá determinar en su decisión el alcance y la magnitud de los daños, pérdidas y perjuicios causados a las víctimas o a sus causahabientes, indicando los principios en que se funda". La redacción es oscura: aparentemente se faculta a la corte para atenerse a los principios que ha adoptado, pero también se dice que la corte, a la hora de resolver la reparación en el caso concreto, deberá indicar los principios, establecidos por ella misma, en los que funda su determinación.

122 Es más amplia la legitimación para solicitar medidas de protección. En este caso el requerimiento puede provenir del fiscal, la defensa, la víctima o el representante legal de ésta, además de que siempre existe la posibilidad de que la corte las ordene de oficio (regla 87). 
carácter excepcional que tiene la decisión de oficio. Ahora bien, puede suceder que el interesado no haga la reclamación ante la CPI y esta misma no supla, de oficio, la omisión de la víctima. Tal omisión no debiera conducir a la pérdida del derecho sustantivo de la víctima, que sería una consecuencia extremosa.

También es posible que la ley nacional contenga disposiciones más favorables para la víctima que las previstas en los principios sobre reparación establecidos por la corte. En estos casos la víctima podría formular ante los tribunales internos, conforme a la ley doméstica, la pretensión de resarcimiento. Esto se deduce del propio estatuto, que previene: "Nada de lo dispuesto en el presente artículo (el 75) podrá interpretarse en perjuicio de los derechos de las víctimas con arreglo al derecho interno o el derecho internacional". ${ }^{123}$ Así nos hallaríamos ante otra hipótesis de "recuperación de la competencia por la justicia nacional".

\section{Otros responsables}

Ya dije que el estatuto no limita la persecución internacional a los principales responsables —-como ocurrió en Nüremberg y se estipula en Sierra Leona-, sino la extiende a todas las personas que hubiesen incurrido en responsabilidad criminal conforme a las reglas que a este respecto fija el propio ordenamiento (artículo 25.3). Sin embargo, es posible que algunos responsables no sean investigados por el fiscal ni procesados por la CPI. Esto no impedirá que la jurisdicción nacional se ejerza con respecto a esos participantes. Las cortes penales no podrán abrir causas ya tramitadas ante la Corte Penal Internacional -identificables por la identidad de los hechos, las personas y las referencias de responsabilidad-, y las resoluciones que en su caso se dicten no afectarán, desde luego, los pronunciamientos que hubiese emitido el tribunal internacional.

123 Por lo que toca al derecho internacional de los derechos humanos, para el planteamiento ante una jurisdicción de este carácter de un asunto ya conocido por la CPI, habria que analizar el alcance de la estipulación sobre inadmisibilidad de una petición o comunicación contenida en el artículo 47.d de la Convención Americana sobre Derechos Humanos: la Comisión Interamericana declarará inadmisible la petición o comunicación que se le presente cuando "sea sustancialmente la reproducción de petición o comunicación anterior ya examinada por la Comisión u otro organismo internacional" (énfasis agregado). 